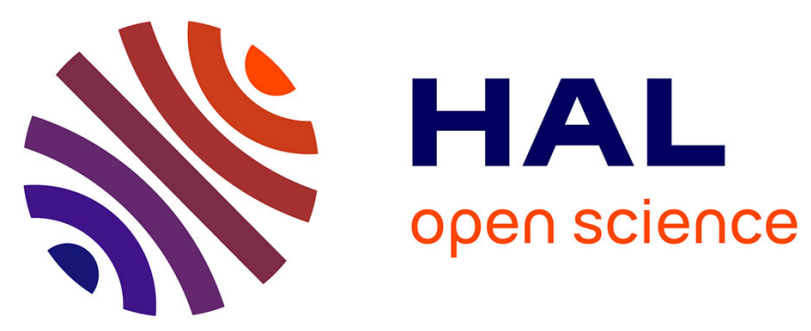

\title{
Numerical Benchmark for High-Reynolds-Number Supercritical Flows with Large Density Gradients
}

Anthony M. Ruiz, Guilhem Lacaze, Joseph C. Oefelein, Raphaël Mari, Bénédicte Cuenot, Laurent Selle, Thierry Poinsot

\section{To cite this version:}

Anthony M. Ruiz, Guilhem Lacaze, Joseph C. Oefelein, Raphaël Mari, Bénédicte Cuenot, et al.. Numerical Benchmark for High-Reynolds-Number Supercritical Flows with Large Density Gradients. AIAA Journal, 2015, vol. 54 (n 5), pp. 1445-1460. 10.2514/1.J053931 . hal-01321259

\section{HAL Id: hal-01321259 \\ https://hal.science/hal-01321259}

Submitted on 25 May 2016

HAL is a multi-disciplinary open access archive for the deposit and dissemination of scientific research documents, whether they are published or not. The documents may come from teaching and research institutions in France or abroad, or from public or private research centers.
L'archive ouverte pluridisciplinaire HAL, est destinée au dépôt et à la diffusion de documents scientifiques de niveau recherche, publiés ou non, émanant des établissements d'enseignement et de recherche français ou étrangers, des laboratoires publics ou privés. 


\section{Open Archive TOULOUSE Archive Ouverte (OATAO)}

OATAO is an open access repository that collects the work of Toulouse researchers and makes it freely available over the web where possible.

This is an author-deposited version published in : http://oatao.univ-toulouse.fr/ Eprints ID : 15675

To link to this article : DOI:10.2514/1.J053931

URL : http://dx.doi.org/10.2514/1.J053931

To cite this version : Ruiz, Anthony M. and Lacaze, Guilhem and Oefelein, Joseph C. and Mari, Raphaël and Cuenot, Bénédicte and Selle, Laurent and Poinsot, Thierry Numerical Benchmark for High-ReynoldsNumber Supercritical Flows with Large Density Gradients. (2015) AIAA Journal, vol. 54 ( $\mathrm{n}^{\circ}$ 5). pp. 1445-1460. ISSN 0001-1452

Any correspondence concerning this service should be sent to the repository administrator: staff-oatao@,1istes-diff.inp-toulouse.fr 


\title{
Numerical Benchmark for High-Reynolds-Number Supercritical Flows with Large Density Gradients
}

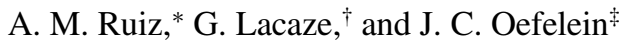 \\ Sandia National Laboratories, Livermore, California 94551 \\ R. Mari $\underline{\S}$ and B. Cuenot $\mathbb{I}$ \\ Centre Européen de Recherche et de Formation Avancée, en Calcul Scientifique, \\ Cedex 0131057 Toulouse, France \\ and

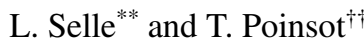 \\ Université de Toulouse, F-31400 Toulouse, France
}

DOI: $\underline{10.2514 / 1 . J 053931}$

\begin{abstract}
Because of the extreme complexity of physical phenomena at high pressure, only limited data are available for solver validation at device-relevant conditions such as liquid rocket engines, gas turbines, or diesel engines. In the present study, a two-dimensional direct numerical simulation is used to establish a benchmark for supercritical flow at a high Reynolds number and high-density ratio at conditions typically encountered in liquid rocket engines. Emphasis has been placed on maintaining the flow characteristics of actual systems with simple boundary conditions, grid spacing, and geometry. Results from two different state-of-the-art codes, with markedly different numerical formalisms, are compared using this benchmark. The strong similarity between the two numerical predictions lends confidence to the physical accuracy of the results. The established database can be used for solver benchmarking and model development at conditions relevant to many propulsion and power systems.
\end{abstract}

\section{Nomenclature}

$C=$ constant of the Papamoschou/Roshko model

$D_{i j}=$ matrix of binary diffusion coefficients, $\mathrm{m}^{2} / \mathrm{s}$

$D_{k}=$ diffusion coefficient of species $k, \mathrm{~m}^{2} / \mathrm{s}$

$d t \quad=\quad$ time step, $\mathrm{s}$

$E \quad=\quad$ total energy per unit mass, $\mathrm{J} / \mathrm{kg}$

$e \quad=$ sensible energy per unit mass, $\mathrm{J} / \mathrm{kg}$

$e_{c} \quad=\quad$ kinetic energy per unit mass, $\mathrm{J} / \mathrm{kg}$

$f \quad=$ frequency, $\mathrm{Hz}$

$h \quad=\quad$ lip height, $\mathrm{m}$

$h n=$ label for mesh with $n$ cells within the lip height (where $n$ is equal to $30,100,250$, or 500 )

$\bar{h}_{k}=$ partial enthalpy of species $\mathrm{k}, \mathrm{J} / \mathrm{kg}$

$J_{j, k}=j$ th component of the diffusive flux of species $\mathrm{k}, \mathrm{kg} \cdot$ $\mathrm{m}^{-2} \cdot \mathrm{s}^{-1}$

$k=$ species index representing $\mathrm{H}_{2}$ or $\mathrm{O}_{2}$

$L_{\mathrm{dc}}=$ dense-core length, $\mathrm{m}$

$M=$ momentum-flux ratio
*Postdoctoral Appointee, Combustion Research Facility, 7011 East Avenue; ruizanthony@gmail.com.

'Senior Member of the Technical Staff, Combustion Research Facility, 7011 East Avenue.

${ }^{\ddagger}$ Distinguished Member of the Technical Staff, Combustion Research Facility, 7011 East Avenue.

${ }^{\S}$ Ph.D. Student, CFD Team, 42 Avenue Coriolis.

'Senior Research Fellow, CFD Team, 42 Avenue Coriolis.

**Research Scientist, INPT/UPS, Institut de Mécanique des Fluides de Toulouse (IMFT), Allée Professeur Camille Soula; also Centre National de la Recherche Scientifique, IMFT, 31400 Toulouse, France.

${ }^{\dagger}$ Research Director, INPT/UPS, Institut de Mécanique des Fluides de Toulouse (IMFT), Allée Professeur Camille Soula; also Centre National de la Recherche Scientifique, IMFT, 31400 Toulouse, France.

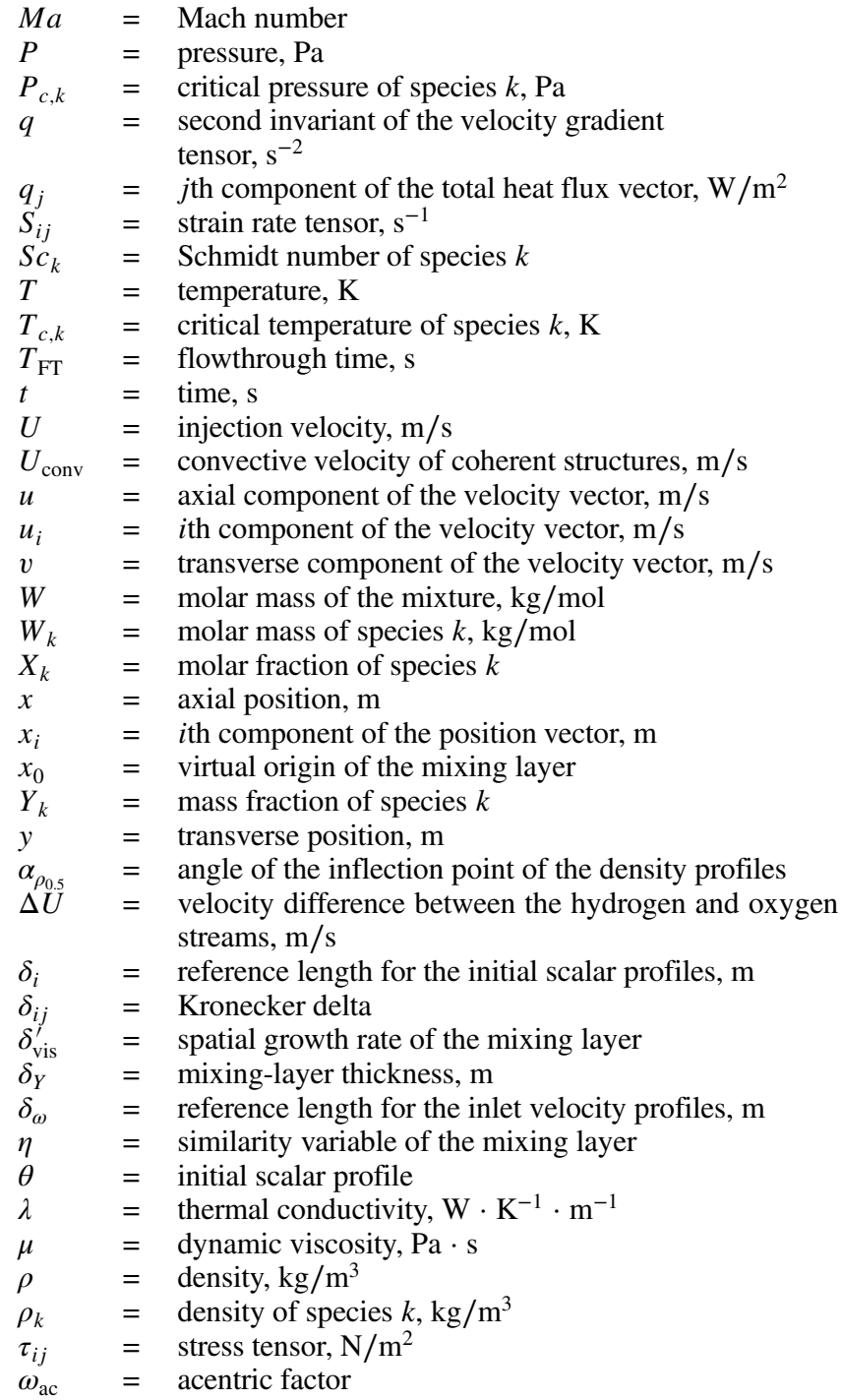




\section{Introduction}

$\mathbf{T}$ URBULENT mixing and combustion at high pressures occur in many high-performance propulsion and power systems such as liquid rocket engines (LREs), diesel engines, and modern gas turbines. These systems are characterized by large Reynolds numbers and large density ratios between the propellants. Chamber pressures often exceed the thermodynamic critical pressure of the injected fluids, which involves significant phenomenological changes in the dynamics of both nonreacting and reacting flows. At subcritical pressure, mixing is dominated by atomization and evaporation of droplets, whereas at supercritical pressure, mixing is mainly governed by turbulent mixing and diffusion. A comprehensive description of available experimental work at high pressure was presented in the reviews of Oschwald et al. [1] and Chehroudi [2]. The configurations that are generally studied are dense liquid jets injected in a chamber of quiescent gaseous mixture and assisted by a coaxial stream. For such nonreacting conditions, the data available include 1) mean longitudinal profiles of a scalar (temperature, density, or mass fraction) along the jet axis [3], 2) radial profiles of a scalar downstream of the jet exit [4-7], and 3) measurements of the "dense-core" (also called "dark-core") length [7-10] and jet angle $[6,11]$. A problem at these conditions, however, is that the space and time resolution of the measurements are limited by beam-steering and line-of-sight spatial averaging. This prevents quantification of the intermediate and small scales of turbulence, which in turn prevents thorough validation of computational fluid dynamics (CFD) calculations.

In addition to the lack of validation data, many ambiguities remain to be solved in numerical tools. At a physical level, the treatment of high-pressure thermodynamics requires sophisticated methods to account for the nonlinearities occurring near the pseudoevaporation line. At the numerical level, advanced schemes and stabilization methods must be employed to limit errors and preserve accuracy. To address these challenges, various three-dimensional direct numerical simulations (DNSs) have been carried out at reduced Reynolds numbers and low density ratios [12-18]. These investigations have shown the impact of high-pressure nonidealities on mixing in threedimensional temporal mixing layers. However, a three-dimensional DNS at device conditions involves large Reynolds numbers and a large density ratio, which requires extremely fine grids. Such computations are not feasible, even with the best supercomputers available today.

Another approach to treat these types of flow is the large-eddy simulation (LES) technique. LES has been employed to predict highReynolds-number flows at elevated pressures [19-32]. In these studies, extreme gradients are created by the coupling of very large density ratios and strong turbulent strain rates inside complex shear layers. Since the resolution of all scales is not possible, various methods have been tested to avoid spurious numerical oscillations. In the works by Oefelein and Yang [19], Oefelein [20], and Zong et al. [22], upwinding of the convective fluxes was used to transport stiff scalar gradients. In the work by Schmitt et al. [27], artificial viscosity was added to the species transport equations, coupled with a pressure correction term in the energy equation. Similar artificial stabilization approaches have been developed in works by Terashima et al. [30] and Terashima and Koshi [31] considering different tradeoffs between errors and energy conservation. Despite the high level of sophistication of these methods, the absence of detailed data for validation can significantly limit the development of predictive models at such extreme conditions.

The objective of the present work is to provide accurate numerical benchmark data in a configuration containing the essential features of real devices (geometry, thermodynamics, and hydrodynamics) while being simple enough to make it accessible to other research groups using different types of numerical approaches (structured, unstructured, DNS, LES, and Reynolds-averaged Navier-Stokes). A two-dimensional DNS approach has been used with two state-of-theart solvers having distinct numerical formalisms. The DNS resolution is verified through a grid-convergence study, which has never been conducted in such a configuration, and which quantifies the required spatial resolution to capture all physical details.

We describe the benchmark configuration in Sec. II. A concise description of the two CFD solvers is given in Sec. III. In Sec. IV.A, details on the procedure used to obtain statistics $\overline{\text { are provided. In }}$ Sec. IV.B, a grid-convergence study is undertaken to determine the spatial resolution required to attain grid independence. In Sec. IV.C, we compare numerical results to available experimental data. And, finally, in Secs. IV.D-IV.F, the detailed numerical results obtained by the two solvers are compared to thoroughly assess the physical content of the provided benchmark data.

\section{Benchmark Configuration}

\section{A. Description of the Case}

The goal of the present case is to provide a platform to benchmark solver accuracy in the context of highly turbulent flows with large density ratios. The configuration has been selected based on the following considerations: 1) relevant conditions for real devices such as rocket combustors and diesel engines (large Reynolds number, typical characteristic size, detailed real-fluid thermodynamics, and transport), 2) representative geometrical features (including injector lip, in contrast with temporal mixing layers studied in the literature), 3 ) precise control of boundary conditions to facilitate accessibility by different solvers, and 4) computational affordability.

To comply with all the previously listed requirements, we consider a two-dimensional mixing layer with an injector lip that separates liquid-oxygen (LOX) and gaseous-hydrogen $\left(\mathrm{GH}_{2}\right)$ streams at supercritical pressure with respect to oxygen. As shown in Fig. 1, this configuration is generically representative of a cryogenic coaxial injector, where a central dense oxygen jet is exposed to shear by a high-speed coaxial hydrogen stream. This configuration allows good control of mixing and flame stabilization in real engines, and it has been studied by several teams [19-21,23,24].

The gray frame in Fig. 1a represents the two-dimensional simulation domain, which is shown in Fig. 1b. The geometrical simplicity of the computational domain allows the use of the same mesh in structured and unstructured solvers, which removes ambiguities linked to the mesh type. Note that, for benchmarking purposes, we solve the two-dimensional Navier-Stokes equations

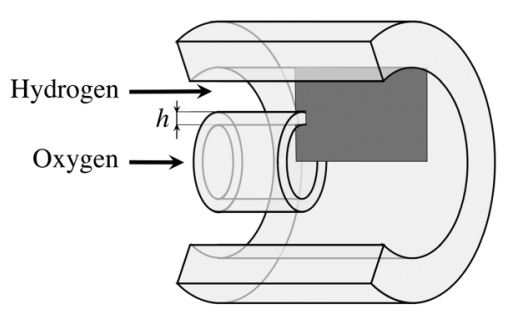

a)

Fig. 1

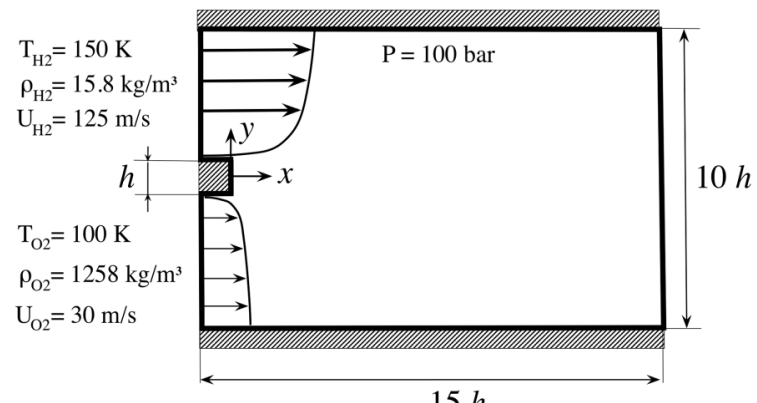

$15 h$ 
instead of the axisymmetric equations. Planar two-dimensional (2-D) calculations provide a better canonical choice for two reasons. First, solving two-dimensional equations is accessible to all CFD solvers, and this makes the benchmark readily usable by the community. Second, the highly unsteady precession of the core and/or turbulent mixing that exists in an actual coaxial injector is not strictly axisymmetric. This can lead to abnormally long liquid penetration at the centerline, which is an undesirable circumstance from a benchmarking perspective. Even though a two-dimensional simulation has potential limitations in terms of turbulent mixing characteristics, a three-dimensional simulation has serious limitations as a benchmark configuration due to the computational cost at the inherently high Reynolds numbers. Details related to CPU cost are given in Appendix B. From this perspective, the two-dimensional domain used here provides a good compromise. Note also that Chehroudi et al. [33] compared favorably the opening angle of cryogenic round jets to plane mixing layers, which tends to indicate that eddies are mainly two-dimensional at early stages, close to the injector lip where destabilization occur.

\section{B. Boundary Conditions}

In the present configuration, a lip height of $h=0.5 \mathrm{~mm}$ separates the two streams, which is a realistic value for LREs. The ambient pressure is $P=10 \mathrm{MPa}$, which is about twice as much as the critical point of $\mathrm{O}_{2}(5.04 \mathrm{MPa})$. The inner, dense oxygen jet has a velocity of $U_{\mathrm{O}_{2}}=30 \mathrm{~m} / \mathrm{s}$, and the Mach number is $M a_{\mathrm{O}_{2}}=0.04$. The outer, light hydrogen jet has a velocity of $U_{\mathrm{H}_{2}}=125 \mathrm{~m} / \mathrm{s}$ and a Mach number of $M a_{\mathrm{H}_{2}}=0.12$. The large shear induced by the velocity difference between the jets triggers turbulent mixing. The density ratio between the oxygen stream and the hydrogen stream is equal to 80 , with $\rho_{\mathrm{O}_{2}}=1258 \mathrm{~kg} / \mathrm{m}^{3}$ and $\rho_{\mathrm{H}_{2}}=15.8 \mathrm{~kg} / \mathrm{m}^{3}$. Using the lip height as the reference length and the injection velocity in each stream, the Reynolds number in each stream is defined as

$$
\operatorname{Re}=\rho h U / \mu
$$

where $\mu_{\mathrm{H}_{2}}=5 \times 10^{-6} \mathrm{~Pa} \cdot \mathrm{s}$ and $\mu_{\mathrm{O}_{2}}=4 \times 10^{-4} \mathrm{~Pa} \cdot \mathrm{s}$. Using this definition, we find $R e_{\mathrm{H}_{2}}=2 \times 10^{5}$ and $R e_{\mathrm{O}_{2}}=5 \times 10^{4}$.

The boundary conditions are summarized in Fig. 1b. A 1/7th power law for the inlet velocities in both streams is used to mimic the mean velocity profile in a turbulent pipe flow:

$$
u(y)=U\left(\left(y-y_{\text {wall }}\right) / \delta_{\omega}\right)^{1 / 7}
$$

where $U$ is the injection velocity in each stream, $y-y_{\text {wall }}$ is the distance to the injector wall, and $\delta_{\omega}=4.5 h$. The Reynolds number is sufficiently large in each stream for the flow to transition to turbulence in the wake of the lip. No velocity perturbations are added to the inflow to maintain the simplicity and repeatability of the boundary conditions. The present study does not focus on wallgenerated turbulence but instead on the interactions between dense and light streams. Adding synthetic turbulence at the inlet and attempting to model wall effects would complicate the comparison between solvers.

The thickness of the vorticity profile at the inlet, as well as the height of the injector lip, determines the characteristics (wavelength and frequency) of the coherent structures developing in the turbulent mixing layer downstream of the injector [34]. The value of $\delta_{\omega}=4.5 \mathrm{~h}$ gives an inlet momentum thickness that is comparable to the lip height $h$ so that the flow is characterized by only one characteristic length scale. The upper and lower boundaries are symmetric, whereas the lip is treated as an adiabatic no-slip wall. The exit plane pressure is $10 \mathrm{MPa}$.

\section{Initial Conditions}

To initialize the simulation, the inlet boundary conditions are swept axially through the entire domain. A hyperbolic tangent profile $\theta(y)$ for the $\mathrm{O}_{2}$ mass fraction and the temperature is used behind the lip $(-0.5 h<y<0.5 h)$ inside a zero-velocity zone, as shown in Fig. 2. The profile is

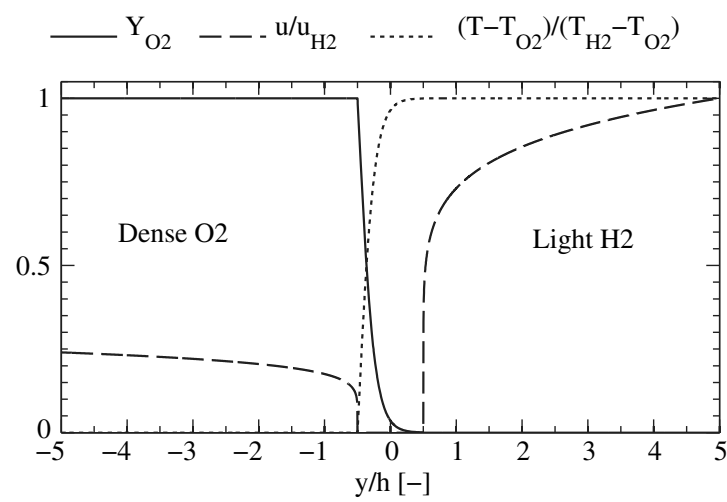

Fig. 2 Transverse cut through the initial solution downstream of the lip $\left(T_{\mathrm{H}_{2}}=150 \mathrm{~K}, T_{\mathrm{O}_{2}}=100 \mathrm{~K}, u_{\mathrm{H}_{2}}=125 \mathrm{~m} / \mathrm{s}\right.$, and $\left.h=0.5 \mathrm{~mm}\right)$.

$$
\theta(y)=\tanh \left(\left(y-y_{\text {wall, } \mathrm{O}_{2}}\right) / \delta_{i}\right)
$$

where $y_{\text {wall, } \mathrm{O}_{2}}=-0.5 h$ and $\delta_{i}=h / 4$. The temperature and mass fraction profiles are

$$
\begin{gathered}
T(y)=T_{\mathrm{O}_{2}}+\left(T_{\mathrm{H}_{2}}-T_{\mathrm{O}_{2}}\right) \theta(y) \\
Y_{\mathrm{H}_{2}}(y)=\theta(y)
\end{gathered}
$$

The thickness of the hyperbolic tangent profile is chosen so that the oxygen and temperature gradient thicknesses are initially resolved with more than five grid points with the coarsest mesh spacing, which has 30 points within the lip height. The grid and spatial resolution are described in detail in Sec. IV.B. The initial conditions do not have any impact on the final results, as transients are flushed during the initialization phase before recording any statistics. The procedure to obtain statistics independent of initial conditions is presented in Sec. IV.A.

\section{Geometry and Grid}

The dimensions of the configuration are presented in Fig. 1b. The lip is $1 h$ long. The computational domain is $10 h$ in the (transverse) $y$ direction and $15 h$ in the (axial) $x$ direction. The region of interest extends axially from 0 to $10 \mathrm{~h}$. A sponge layer is placed before the exit to prevent spurious acoustic wave generation due to outgoing hydrodynamic structures. To avoid any undesirable effects of stretching in the region where eddies develop, the grid spacing is constant across a span of $3 h$ in the $y$ direction (centered on the lip) and $10 h$ in the $x$ direction. To minimize computational cost, stretching is applied outside this region, where no eddies are present using a factor of $1 \%$ in the $y$ direction only.

\section{Description of the Solvers}

To establish quantitative benchmark data that are independent of the solver used, we have performed back-to-back comparisons of the results using two different solvers. Each has distinct state-of-the-art numerical frameworks. The initialization, boundary conditions, and physical models are applied consistently between these solvers.

AVBP is a massively parallel CFD solver codeveloped by Centre Européen de Recherche et de Formation Avancée en Calcul Scientifique and IFP Energies Nouvelles. AVBP has been used in many different industrial applications, ranging from gas turbines [35-37] and piston engines $[\underline{38}, \underline{39}]$ to scramjets [40]. An overview of the solver properties and recent applications were presented in works by Gourdain et al. $[\underline{41}, \underline{42}]$. In the context of supercritical studies, AVBP has been used to study nonreacting supercritical nitrogen round jets $[27,29]$ and in the reacting studies of coaxial jets $[28,43]$.

RAPTOR is a massively parallel CFD solver, for which the theoretical and numerical framework was described by Oefelein [20]. The code is designed to provide a unified treatment of highReynolds-number high-pressure real-gas/liquid reacting flows over a wide Mach operating range. It has been used to study nonreacting and 
reacting flows at rocketlike conditions $[\underline{19}-21,44]$ and to investigate transient injection processes relevant to internal combustion engines $[\underline{45}, \underline{46}]$.

\section{A. Theoretical Framework}

1. Governing Conservation Equations

In this study, an Eulerian formulation is adopted to represent the $\mathrm{O}_{2} / \mathrm{H}_{2}$ supercritical mixing layer. This formulation assumes that surface tension is negligible relative to aerodynamic forces, which appears correct in the light of experimental studies of cryogenic flows (see Sec. I).

The conservation equations describing the evolution of a compressible flow are

$$
\begin{gathered}
\frac{\partial \rho u_{i}}{\partial t}+\frac{\partial \rho u_{i} u_{j}}{\partial x_{j}}=-\frac{\partial}{\partial x_{j}}\left[P \delta_{i j}-\tau_{i j}\right] \\
\frac{\partial \rho E}{\partial t}+\frac{\partial \rho E u_{j}}{\partial x_{j}}=-\frac{\partial}{\partial x_{j}}\left[u_{i}\left(P \delta_{i j}-\tau_{i j}\right)+q_{j}\right] \\
\frac{\partial \rho_{k}}{\partial t}+\frac{\partial \rho_{k} u_{j}}{\partial x_{j}}=-\frac{\partial}{\partial x_{j}}\left[J_{j, k}\right]
\end{gathered}
$$

Equations (6-8) correspond to the conservation laws for momentum, total energy, and species, respectively, where $\rho, u_{i}, E$, and $\rho_{k}$ denote the density, the $i$ th component of the velocity vector, the total energy per unit mass $\left(E=e_{c}+e\right.$, with $e_{c}$ as the kinetic energy and $e$ as the sensible energy), and the density of the species $k$ : $\rho_{k}=\rho Y_{k}$ for $k=1$ to $N$ (where $N$ is the total number of species), with $Y_{k}$ being the mass fraction of the $k$ th species. $P$ denotes the pressure, $\tau_{i j}$ denotes the stress tensor [defined in Eq. (11)], $\boldsymbol{q}_{j}$ is the heat flux vector [defined in Eq. (13)], and $\boldsymbol{J}_{j, k}$ is the vector of the diffusive flux of species $k$ [defined in Eq. (9)]. The gravity force is neglected here, since high-performance devices are typically driven by forced convection.

The diffusive species flux for each species $k$ is modeled as

$$
\boldsymbol{J}_{i, k}=-\rho\left(D_{k} \frac{W_{k}}{W} \frac{\partial X_{k}}{\partial x_{i}}-Y_{k} V_{i}^{c}\right)
$$

where $D_{k}$ represents the diffusion coefficients for each species $k$ in the mixture, $W_{k}$ is the molar mass of species $k, W$ is the molar mass of the mixture, and $X_{k}$ is the molar fraction of species $k$. Using the recommendations of Poinsot and Veynante [47], the $i$ th component of the correction diffusion velocity $V_{i}^{c}$ is given by
Table 1 Species critical-point

properties (temperature $T$, pressure

$P$, and acentric factor $\left.\omega_{\text {ac }}\right)$

\begin{tabular}{lcc}
\hline \hline Parameters & $\mathrm{H}_{2}$ & $\mathrm{O}_{2}$ \\
\hline$T_{c, k}, \mathrm{~K}$ & 33 & 154.581 \\
$P_{c, k}, \mathrm{MPa}$ & 1.2838 & 5.0430 \\
$\omega_{\mathrm{ac}}$ & -0.216 & 0.0222 \\
\hline \hline
\end{tabular}

$$
V_{i}^{c}=\sum_{k=1}^{N} D_{k} \frac{W_{k}}{W} \frac{\partial X_{k}}{\partial x_{i}}
$$

The stress tensor $\tau_{i j}$ is given by

$$
\tau_{i j}=2 \mu\left(S_{i j}-\frac{1}{3} \delta_{i j} S_{l l}\right)
$$

where $S_{i j}$ is the rate of strain tensor, and $\mu$ is the dynamic viscosity:

$$
S_{i j}=\frac{1}{2}\left(\frac{\partial u_{i}}{\partial x_{j}}+\frac{\partial u_{j}}{\partial x_{i}}\right)
$$

The total heat flux vector then takes the form

$$
q_{i}=-\lambda \frac{\partial T}{\partial x_{i}}+\sum_{k=1}^{N} J_{i, k} \bar{h}_{k}
$$

where $\lambda$ is the heat conduction coefficient of the mixture (see Sec. III.A.2.b), and $\bar{h}_{k}$ is the partial enthalpy of the species $k$ [48]. The computation of the heat, momentum, and mass coefficients is outlined in Sec. III.A.2.b.

\section{Real-Fluid Model for Supercritical Fluids}

a. Equation of State. To account for real-gas effects, cubic equation of states (EOSs) offer a good tradeoff between cost and accuracy. Figure 3 a shows the density of pure oxygen at $P=10 \mathrm{MPa}$ as a function of temperature using the Peng-Robinson (PR) [49]EOS, the Soave-Redlich-Kwong (SRK) [50] EOS, the ideal-gas law, and National Institute of Standards and Technology (NIST) reference data [51]. At $T=100 \mathrm{~K}$, the relative errors to NIST data are 1, 13, and $6 \overline{5 \%}$ with the SRK, PR, and ideal-gas EOSs, respectively. The SRK EOS is typically more accurate at low temperatures (100 to $150 \mathrm{~K}$ ), whereas the PR EOS is more accurate when thermal expansion is large, as observed between 150 and $200 \mathrm{~K}$ in Fig. 3a. More accurate EOSs also exist, such as the 32-term Benedict-WebbRubin EOS [52], but their increased level of sophistication and
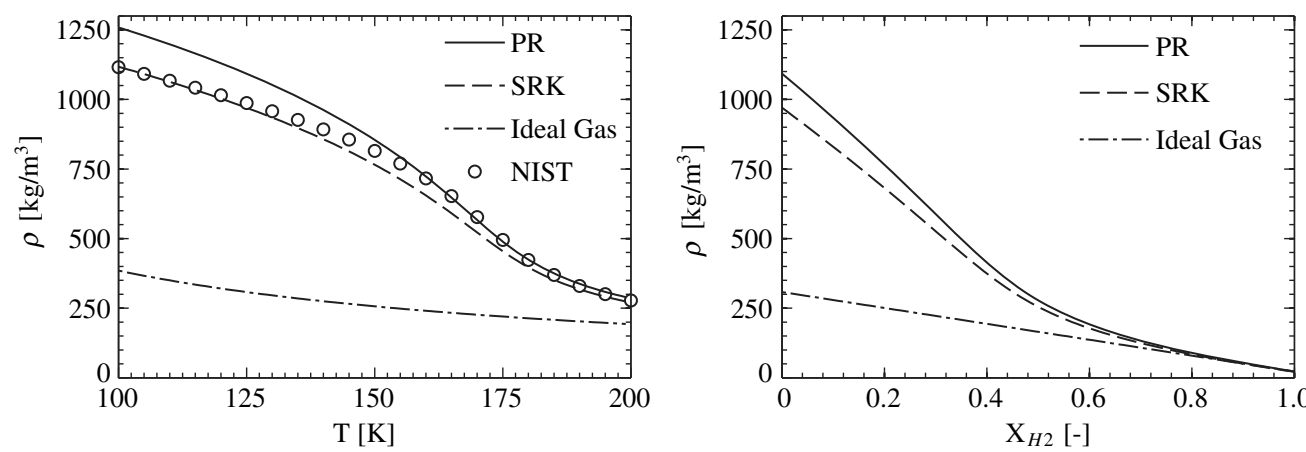

a)

b)

Fig. 3 Real-gas effects on density for a) oxygen at $P=10 \mathrm{MPa}$ and variable temperature; and b) a binary $\mathrm{H}_{2} / \mathrm{O}_{2}$ mixture with variable composition, at $T=125 \mathrm{~K}$ and $P=10 \mathrm{MPa}$. 
computational cost make them less suited for CFD. Here, we use the PR EOS in both solvers given the current scope, with the numerical values of the critical parameters listed in Table 1 . This choice was motivated by the greater accuracy of PR in the high-temperature range, which makes it a better candidate for subsequent reacting flow studies. Figure $3 \mathrm{~b}$ also highlights real-gas effects on density for a binary $\mathrm{H}_{2} / \mathrm{O}_{2}$ mixture with variable composition, at $T=125 \mathrm{~K}$ and $P=10 \mathrm{MPa}$. For an ideal gas, density is a linear function of composition. For a real gas, a strong departure from linearity is observed when the mixture contains mostly oxygen (for $X_{\mathrm{H}_{2}} \leq 0.5$ ) on Fig. 3 b, whereas a near-ideal behavior is observed in pure hydrogen when the fluid state is well above the critical point of hydrogen (see Table 1). The density is approximately three times larger with the two cubic EOSs than with the ideal-gas law. Many studies have shown the impact of the density ratio on turbulent mixing $[27,53,54]$. Thus, real-gas effects are prevalent in this benchmark. Real-gas EOSs also impact partial derivatives of density and energy, which induce steep spatial variations of thermodynamic coefficients between the hydrogen and oxygen streams.

b. Transport. In AVBP, complex transport coefficients for heat and momentum are modeled using the extended corresponding states methodology developed by Chung et al. $[55,56]$. For multispecies mixtures, this methodology can develop anomalies [57]. Here, a modified version is used, which enables one to maintain accurate behavior in the limit of pure species and good computational efficiency while circumventing diverging values for varying compositions. The transport coefficients for each components of the mixture are first computed separately. Then, coefficients for each species are weighted according to their mass fraction to yield the mixture-average transport coefficients. In Figs. $4 \mathrm{a}$ and $4 \mathrm{~b}$, the transport coefficients computed with this modified version of the Chung et al. methodology are compared to the extended corresponding states methodology developed by Ely and Hanley $[58,59]$, which is used in RAPTOR. The composition of a $\mathrm{H}_{2} / \mathrm{O}_{2}$ binary mixture is varied, with $T=125 \mathrm{~K}$ and $P=10 \mathrm{MPa}$, which is representative of the thermodynamic state of the mixing layer. For this mixture, the modified version of the Chung et al. method used in
AVBP allows one to retrieve a correct behavior for the heat and momentum transport coefficients.

In RAPTOR, the mixture diffusion coefficient for species $k\left(D_{k}\right)$ is computed as a function of the matrix of binary diffusion coefficients $D_{i j}$, as obtained from kinetic theory $[\underline{60}, \underline{61}]$ :

$$
D_{k}=\frac{1-Y_{k}}{\sum_{j \neq k}^{N} X_{j} / D_{j k}}
$$

The pressure correction model of [62] is also taken into account in $D_{k}$. In AVBP, constant Schmidt numbers are used for each species: $S_{c, \mathrm{H}_{2}}=0.3, S_{c, \mathrm{O}_{2}}=1.0$, and the diffusion coefficient is

$$
D_{k}=\frac{\mu}{\rho S_{c, k}}
$$

Figure $4 \mathrm{c}$ shows how the Schmidt number compares between AVBP and RAPTOR. In a low-Reynolds-number flow, the strong assumption made in AVBP will impact scalar profiles; but in the present case, mixing is highly turbulent and the impact of these diffusion coefficients is assumed to be small so that this approximation should be acceptable. This is verified a posteriori in Sec. IV.E, where statistical results do not appear to be very sensitive to these coefficients. Similarly, the Dufour and Soret terms in Eqs. (13) and (9) have been neglected to establish an initial baseline.

\section{B. Numerical Framework}

1. Spatial Discretization Scheme

AVBP uses unstructured meshes and finite volume or finite element high-order differencing stabilized by explicit and localized artificial viscosity. In this study, the TTG4A finite element scheme [63] is exclusively used. This scheme is third-order accurate in space and time.

RAPTOR is a generalized-curvilinear-coordinate multiblock solver. The spatial discretization employs a second-order-accurate

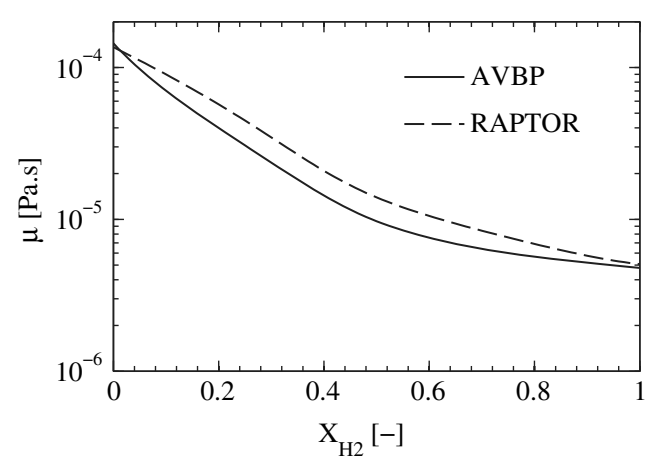

a)

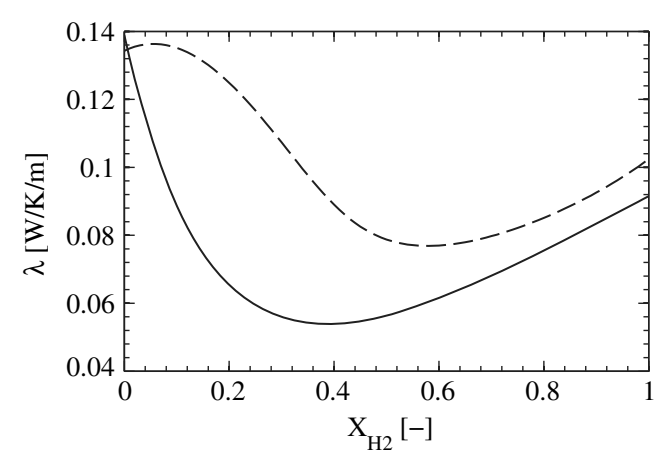

b)

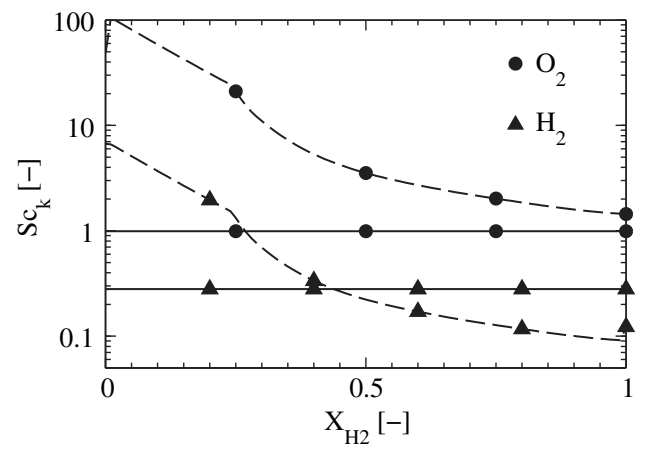

c) 
staggered-grid formulation, where scalar values are stored at cell centers and velocity components are stored at respective cell faces.

\section{Temporal Integration Scheme}

In AVBP, the TTG4A scheme [63] uses a two-step Runge-Kutta explicit time integration, which is third-order accurate in time. The acoustic Courant-Friedrichs-Lewy (CFL) number is dynamically set to 0.9 , which results in an explicit time step of $d t=10^{-9} \mathrm{~s}$ for the $h 250$ mesh used to obtain the database results in Sec. IV (250 cells within the lip height).

The temporal integration scheme implemented in RAPTOR employs an all-Mach-number formulation using the dual-timestepping technique with generalized preconditioning [64-66]. This semi-implicit approach is fourth-order accurate in time. The physical time step is set to $d t=10^{-8} \mathrm{~s}$ for the $h 250$ mesh and 20 inner-loop integrations are conducted at a local convective CFL of 0.5 .

\section{Numerical Stabilization}

In the present case, the high level of turbulence coupled with the large density ratio lead to sharp velocity and scalar gradients. In the two solvers, numerical errors are avoided by using two different approaches.

In AVBP, the numerical stabilization technique is inspired by Schmitt et al. [27], who devised a local artificial dissipation operator dedicated to supercritical computations. The purpose of this operator is to prevent the generation of spurious pressure oscillations that can arise in the vicinity of steep density gradients when real-gas thermodynamics is used. This is accomplished by adding a source term on the energy equation using the exact thermodynamic relation between energy and density at constant pressure. More details are given in the work by Schmitt et al. [27].

In RAPTOR, the stabilization method is based on convective switching. This strategy comes from shock capturing methods [67-69] and has been adapted to supercritical flows with high-density gradients [66]. The flux correction switches from a second-order quadratic upstream interpolation for convective kinematics scheme in flow regions where no numerical difficulty is detected to a firstorder upwind scheme in zones requiring stabilization. The overall strategy ensures total variation diminishing properties.

\section{Implementation of Boundary Conditions}

In AVBP, the Navier-Stokes characteristic boundary condition (NSCBC) formalism [70,71] is used and accounts for both real-gas effects [72] and transverse terms [73] at the inlets and the outlet. In RAPTOR, transported variables are imposed at the inlets and extrapolated at the outlet. In both cases, a sponge layer is added in the $x / h \geq 9$ region to prevent spurious acoustic wave generation due to outgoing hydrodynamic structures.

\section{Summary}

Table 2 summarizes the similarities and differences between the setup and code features in AVBP and RAPTOR. The contrast in code features is sufficient so that a similar answer from both solvers will lend confidence in the benchmark results.

\section{Numerical Results}

\section{A. Simulation Sequence and Temporal-Averaging Procedure}

Before analyzing the results, two points need to be clarified.

1) How long does it take to flush the initial solution and reach quasi-steady state?

2) How long should the simulation be run to reach temporal convergence and obtain meaningful statistics?

These two periods are determined using a sufficient number of flowthrough times of coherent structures through the region of interest.

The convective velocity is evaluated using the expression $[\underline{74,75}]$

$$
U_{\text {conv }}=\frac{U_{\mathrm{O}_{2}}+\left(\rho_{\mathrm{H}_{2}} / \rho_{\mathrm{O}_{2}}\right)^{1 / 2} U_{\mathrm{H}_{2}}}{1+\left(\rho_{\mathrm{H}_{2}} / \rho_{\mathrm{O}_{2}}\right)^{1 / 2}}
$$

which gives $U_{\text {conv }}=39.6 \mathrm{~m} / \mathrm{s}$. Other expressions for the convective velocity have also been proposed in the literature [76,77], but they all give the same order of magnitude for the current case [78].

The flowthrough time in the present configuration is then defined using the length of the zone of interest $(10 h)$ :

$$
T_{\mathrm{FT}}=\frac{10 h}{U_{\text {conv }}}=0.125 \mathrm{~ms}
$$

The temporal evolutions of the main quantities $\left(T, P, u, v, Y_{\mathrm{O}_{2}}\right)$ recorded at various locations in the mixing layer showed that steady state is reached after $10 T_{\mathrm{FT}}$, starting from the initial solution.

From $t=10 T_{\mathrm{FT}}$, three different time-averaging periods have been compared: $10 T_{\mathrm{FT}}, 15 T_{\mathrm{FT}}$, and $20 T_{\mathrm{FT}}$. For the comparison, the transverse one-dimensional (1-D) profiles at $x=5 h$ (middle of the mixing layer) have been used, as shown for the mean and root mean square of temperature and velocity in Fig. 5. The other scalars have a similar behavior and are not shown for conciseness. For the mean quantities, $10 T_{\mathrm{FT}}$ is sufficient to obtain well-converged profiles. For the rms velocities, the increase in time-averaging duration from $15 T_{\mathrm{FT}}$ to $20 T_{\mathrm{FT}}$ has a minor impact (less than $5 \%$ relative error) on the convergence. The physical analysis of these transverse profiles is described in Sec. IV.E.

Subsequently, the simulation follows the sequence:

1) Reach steady state by running the computation for $10 T_{\mathrm{FT}}=$ $1.25 \mathrm{~ms}$ from the initial conditions presented in Sec. II.C.

2) Converge the statistics over a period of $15 T_{\mathrm{FT}}=1.83 \mathrm{~ms}$.

\section{B. Effect of Grid Resolution and Convergence}

The objective of this section is to determine the spatial resolution required to obtain grid-independent turbulence statistics for the present benchmark. The grid is progressively refined until the mean and $\mathrm{rms}$ of the transported quantities become insensitive to spatial refinement. A set of simulations using increasingly refined meshes have been conducted. The number of cells within the lip height $h$ are set to $30,100,250$, and 500. In the following, the meshes are called " $h n$," where $n$ is the number of cells within the lip height.

To identify coherent structures in the flowfield, we use the second invariant of the velocity gradient tensor $q$, defined as

\begin{tabular}{|c|c|c|c|c|}
\hline $\begin{array}{l}\text { Common } \\
\text { setup }\end{array}$ & AVBP \& RAPTOR & Contrasting code features & AVBP & RAPTOR \\
\hline Mesh & $\begin{array}{c}\text { Constant spacing with } \\
d x=h / 250 \text { in the lip wake }\end{array}$ & $\begin{array}{l}\text { Transport coefficients of } \\
\text { heat and momentum }\end{array}$ & Modified Chung et al. $[\underline{55}, \underline{56}]$ & Ely and Hanley $[\underline{58}, \underline{59}]$ \\
\hline $\begin{array}{l}\text { Initial } \\
\text { conditions }\end{array}$ & $\begin{array}{l}\text { Well-resolved hyperbolic } \\
\text { tangent profiles }\end{array}$ & $\begin{array}{l}\text { Transport coefficients of } \\
\text { mass }\end{array}$ & $\begin{array}{l}\text { Constant Schmidt numbers: } \\
S_{c, \mathrm{H}_{2}}=0.3, S_{c, \mathrm{O}_{2}}=1.0\end{array}$ & $\begin{array}{l}\text { Binary-diffusion matrix with pressure } \\
\text { correction }[60-62]\end{array}$ \\
\hline $\begin{array}{l}\text { Boundary } \\
\text { conditions }\end{array}$ & $\begin{array}{l}1 / 7 \text { th inlet velocity profile } \\
\text { without flow perturbations }\end{array}$ & Spatial discretization & $\begin{array}{l}\text { TTG4A scheme [63], finite } \\
\text { element, third order centered }\end{array}$ & Finite volume, second order staggered \\
\hline $\begin{array}{l}\text { Equation of } \\
\text { state }\end{array}$ & Peng and Robinson [49] & Temporal discretization & Explicit two-stage Runge-Kutta & $\begin{array}{l}\text { Semi-implicit four-stage Runge-Kutta } \\
\text { with dual-time stepping }[\underline{64}, \underline{65]}\end{array}$ \\
\hline-- & -- & Numerical stabilization & $\begin{array}{l}\text { Artificial viscosity with energy } \\
\text { correction method [27] }\end{array}$ & $\begin{array}{c}\text { Convective switching to first order } \\
\text { upwind [66] }\end{array}$ \\
\hline
\end{tabular}

Table 2 Similarities and differences between the setup and code features in AVBP and RAPTOR 


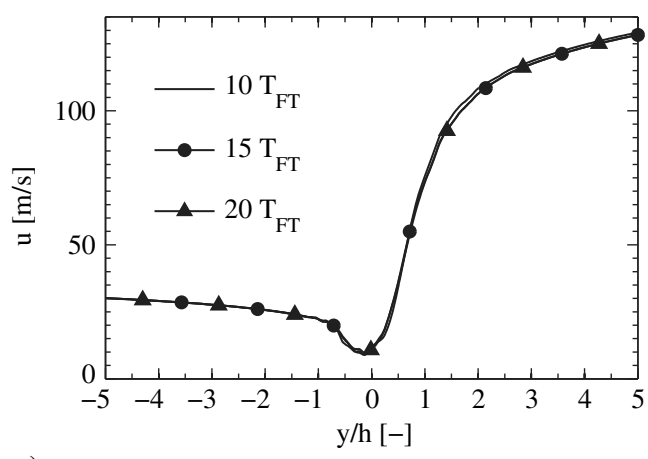

a)

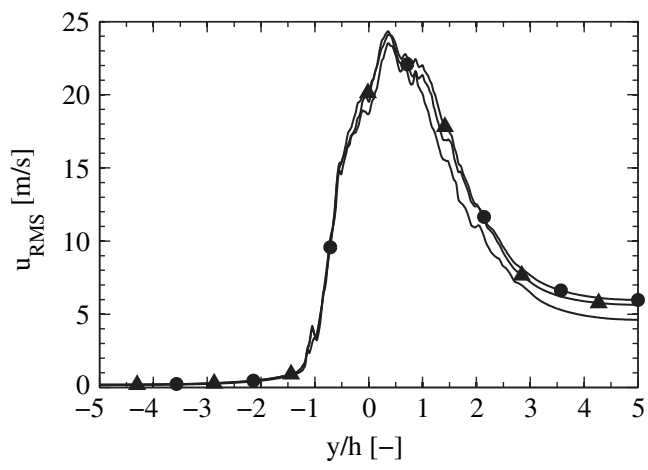

c)

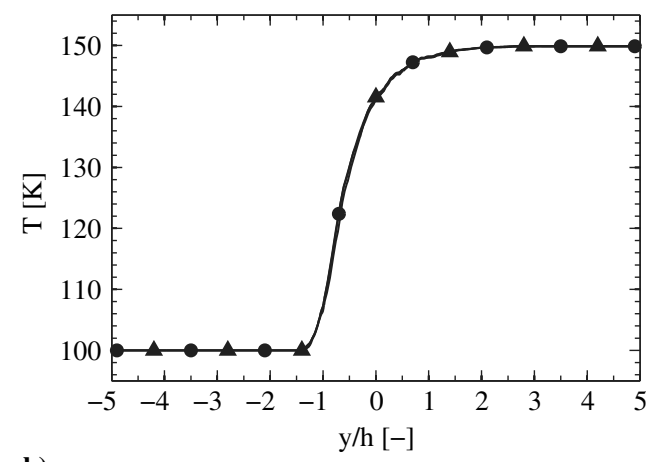

b)

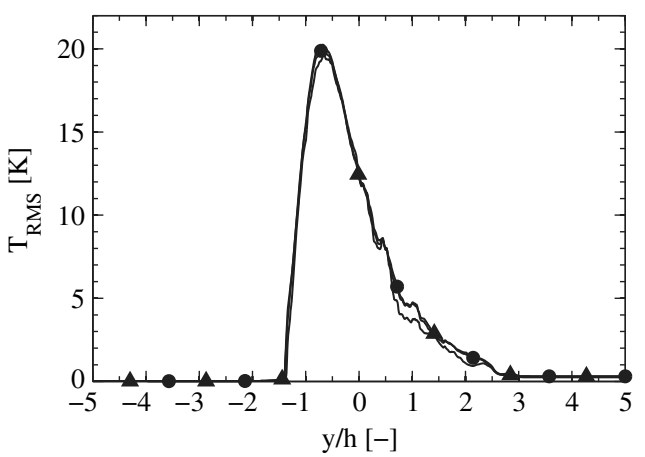

d)

Fig. 5 Impact of time-averaging period on transverse profiles at $x / h=5:$ a) mean axial velocity, b) mean temperature, c) rms axial velocity, and d) rms temperature.

$q=\left(|\Omega|^{2}-|S|^{2}\right) / 2$, with $\Omega$ defined as the spin tensor and $S$ as the strain rate tensor [79]. Fluid particles with a positive $q$ value have more vorticity than strain, which enables one to locate coherent structures in the flow. Figure 6 shows instantaneous snapshots of the density field superimposed with large positive $q$ isocontours $\left(q=10^{12} \mathrm{~s}^{-2}\right)$, colored by vorticity (online version only). The blue

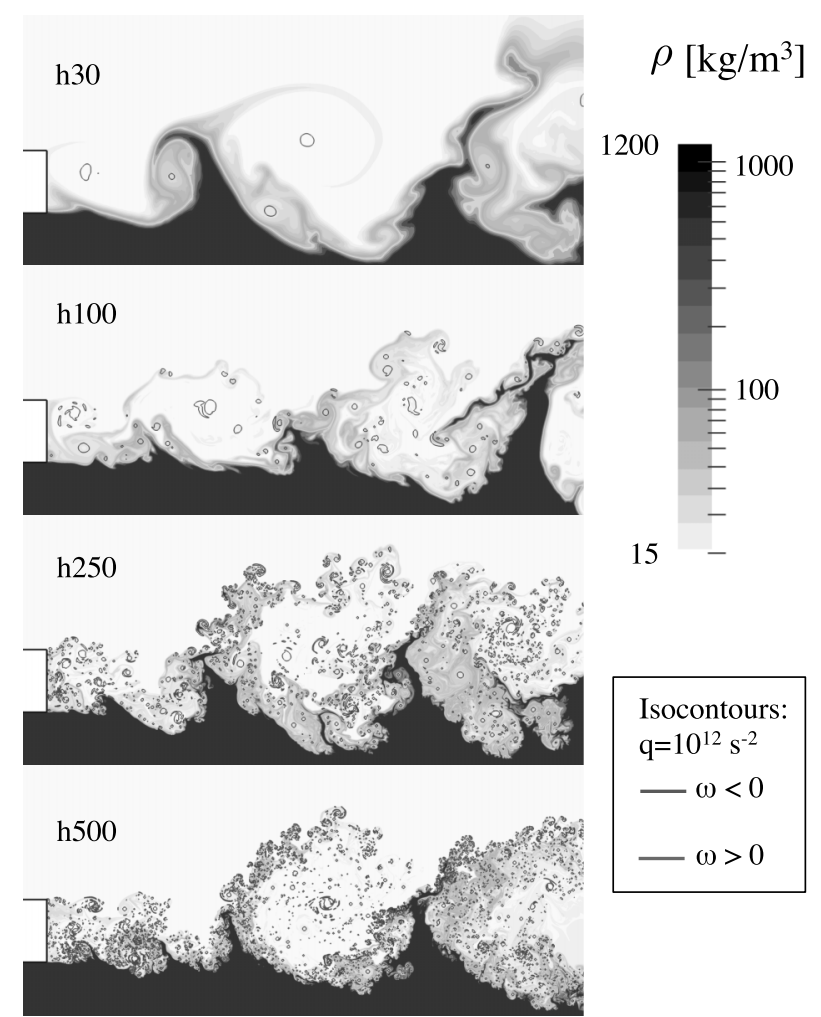

Fig. 6 Instantaneous density fields (log scale) superimposed with $q=10^{12} \mathrm{~s}^{-2}$ isocontours, colored by vorticity (online version only). and red contours in the online version of Fig. 6 indicate negative (clockwise rotation) and positive vorticity (counter-clockwise rotation), respectively.

Similarities can be observed between the four grids. The KelvinHelmholtz mechanism that sheds eddies at the top corner of the lip is captured, even with the coarsest mesh. These large eddies with negative vorticity are shown in Fig. 6. Large-scale disturbances in the density field can be observed as a result of the interactions between the positive and negative vorticity structures with the scalar field. Increasing the resolution clearly impacts turbulence at the smallest scales. This is coupled with an increase of the multiscale wrinkling of the exchange surface between the two streams.

To show the sensitivity of flow statistics to grid resolution, the mean and rms transverse profiles of major quantities have been compared for the different mesh resolutions. The transverse profiles of temperature and axial velocities at $x / h=5$ are presented in Fig. 7 . Very similar trends have been observed at other locations. Although there is a significant impact of mesh resolution between $h 30$ and $h 100$, the time-averaged results are fairly insensitive to mesh resolution beyond $h 100$.

Figure $\underline{8}$ shows the power spectrum density (PSD) of the square of the transverse velocity $v$ using a time-resolved probe located in the mixing-layer region at $x / h=7$ and $y / h=0$ for increasing mesh resolutions. The spectra have two main regions: one with a $-5 / 3$ slope and one with a -3 slope, as indicated in Fig. 8. In twodimensional turbulent flows, the $-5 / 3$ slope indicates a reverseenergy cascade that transfers energy from the small scales to the large scales through amalgamation of vortices. The -3 slope indicates a forward-enstrophy cascade, which transfers energy to the dissipative scales of the flow. These two regions have been predicted by theory $[80,81]$ and have been observed experimentally [82] for homogeneous two-dimensional turbulent flows.

The presence of these two slopes in the turbulent kinetic energy spectrum is an indication that canonical two-dimensional turbulence is accurately predicted in the present simulation. It also indicates the implications of the two-dimensional approximation used in the present work because the transfer of turbulent kinetic energy in a three-dimensional turbulent flow is dominated by the classical forward-energy cascade with a $-5 / 3$ slope. From the numerical 


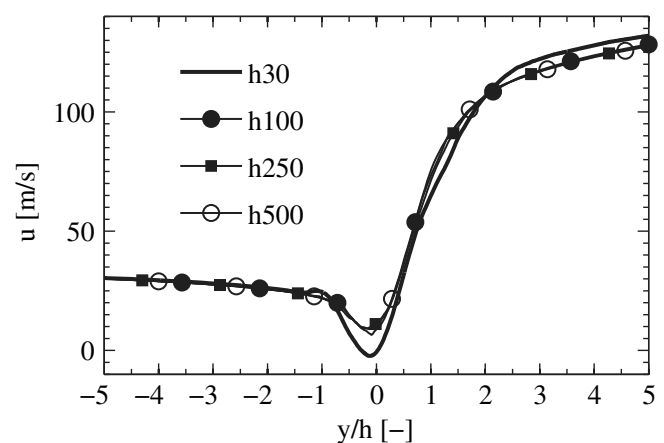

a)

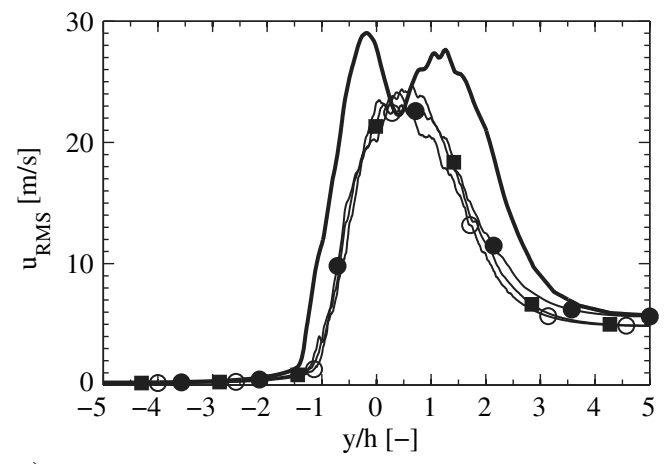

c)

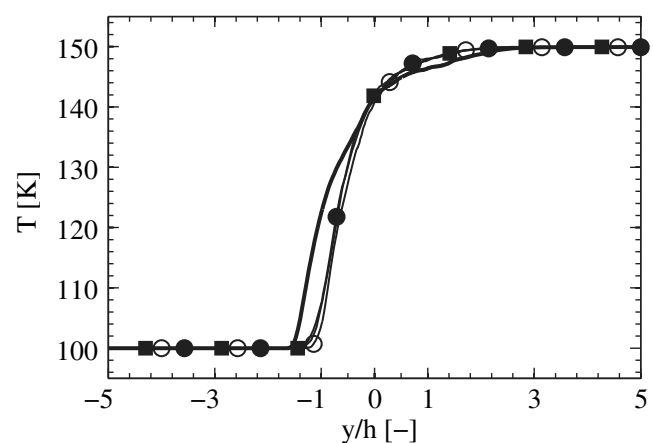

b)

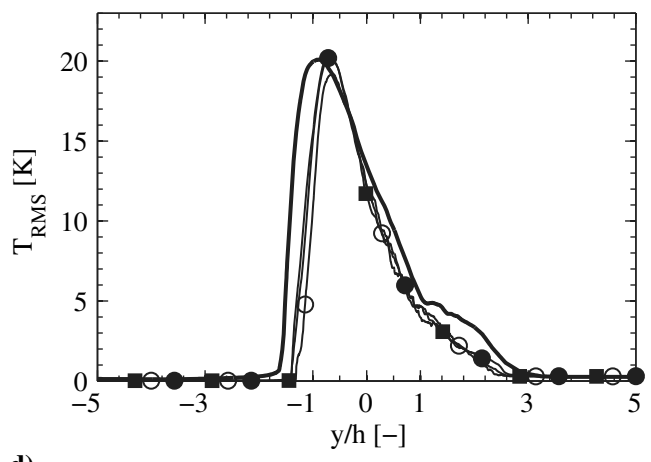

d)

Fig. 7 Mean and rms profiles at $x / h=5$ : a) mean axial velocity, b) mean temperature, c) rms axial velocity, and d) rms temperature.

benchmark perspective, the main challenge is to accurately solve the interaction of strong density gradients with vortical structures, which is a difficulty that is embedded in this two-dimensional configuration. The two-dimensional approximation mainly saves computational time and makes this benchmark accessible to the wider CFD community.

The forward-enstrophy cascade is present in the $h 100, h 250$, and $h 500$ calculations in the high-frequency range $\left(f>3 \times 10^{5} \mathrm{~Hz}\right)$. The $h 30$ mesh is too coarse to capture this range of scales, which implies that dissipation at small scales does not occur. The reverseenergy cascade thus transfers more energy to the large scales, which can explain why the peak and width of the velocity fluctuations presented in Fig. 7 are too large.

The $h 100$ case represents an extreme, where the forwardenstrophy cascade starts to appear but the dissipation of energy artificially occurs at scales larger than the physical dissipative scales due to numerical stabilization. This is consistent with the limited amount of small-scale structures observed in Fig. 6. Because only a small part of the turbulent kinetic energy is contained in the small scales, the mean and rms of the velocities and scalars are still in good agreement with the $h 250$ and $h 500$ cases, as observed in Fig. 7 .

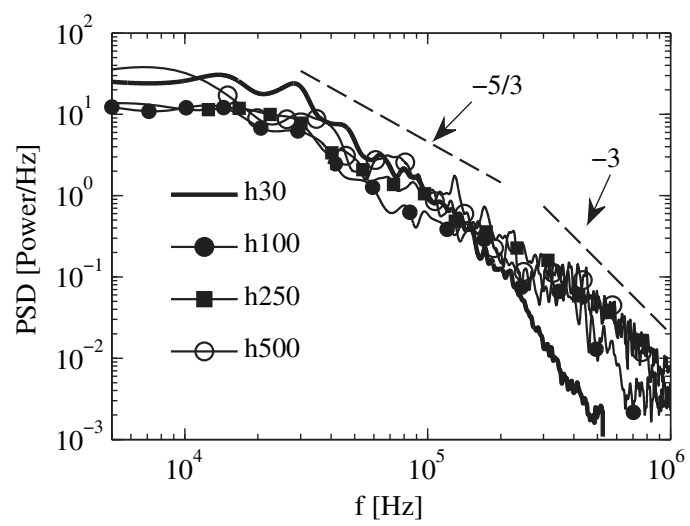

Fig. 8 Power spectrum density of the square of transverse velocity at $(x, y)=(7 h, 0)$ for increasing mesh resolutions.
Appendix $\mathrm{C}$ gives additional details about the scale separation in the present configuration.

Given the results here, the $h 250$ mesh resolution is used for comparing AVBP and RAPTOR results. This helps verify that mean and rms statistics are grid independent and numerical dissipation does not impact vortical structures.

\section{Comparison with Available Experimental Data}

In this section, we compare numerical results to the available experimental measurements of the spreading angle and mixing-layer thickness. These quantities provide good bulk estimates of turbulent mixing. The limitations of a two-dimensional calculation have been acknowledged in the previous sections. The objective of this section is simply to determine how the present benchmark data compare to available experimental results.

Here, the dense-core length $L_{\mathrm{dc}}$ is estimated using the location of the inflection point of the mean density profile. This is based on the premise that experimental shadowgraphs identify a dense core as the region of steepest variation of density, which in turn is responsible for most of the light deviation. From the spatial evolution of the inflection point in the downstream direction, an angle $\alpha_{\rho_{05}}$ is extracted, leading to $L_{\mathrm{dc}} / D=1 /\left(2 \tan \left(\alpha_{\rho_{0.5}}\right)\right)$. With $\alpha_{\rho_{0.5}}=2.2$ and $1.7 \mathrm{deg}$ for AVBP and RAPTOR, we obtain $L_{\mathrm{dc}} / D=13$ and 17, respectively. This is compared to experimental results obtained using shadowgraphy in Fig. 9 (adapted from Chehroudi [2]). The equivalent dense-core length obtained in the present study is in the range of experimental values observed in supercritical coaxial jets at the same momentum-flux ratio. The momentum-flux ratio is defined by

$$
M=\frac{\rho_{\mathrm{H}_{2}} U_{\mathrm{H}_{2}}^{2}}{\rho_{\mathrm{O}_{2}} U_{\mathrm{O}_{2}}^{2}}
$$

which gives $M=0.22$. Although this seems to indicate a correct physical content of the present simulations, one clearly understands the limitation of this comparison in terms of validation. The value of the dense-core length depends on the threshold chosen in both the experiments and simulations, and comparisons are, at best, qualitative. 


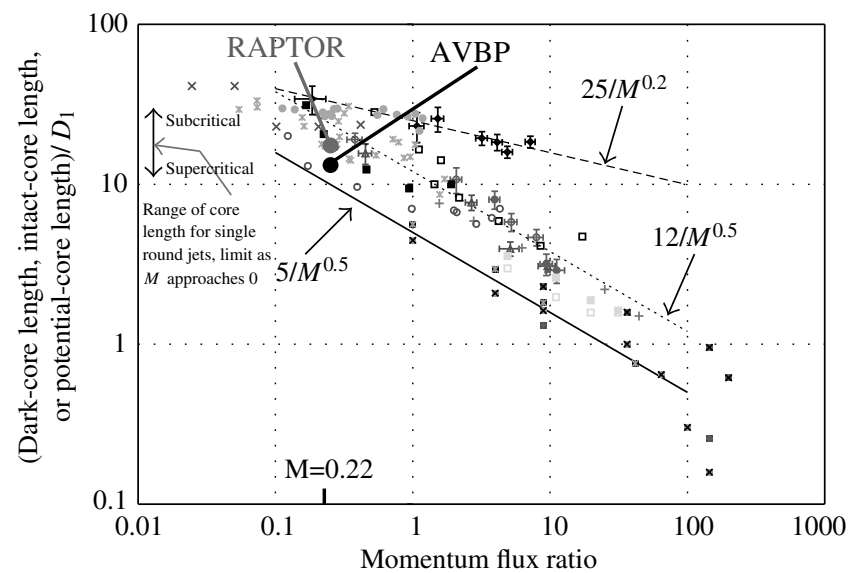

Fig. 9 Comparison of the present dense core lengths with experimental measurements. Graph adapted from work by Chehroudi [2].

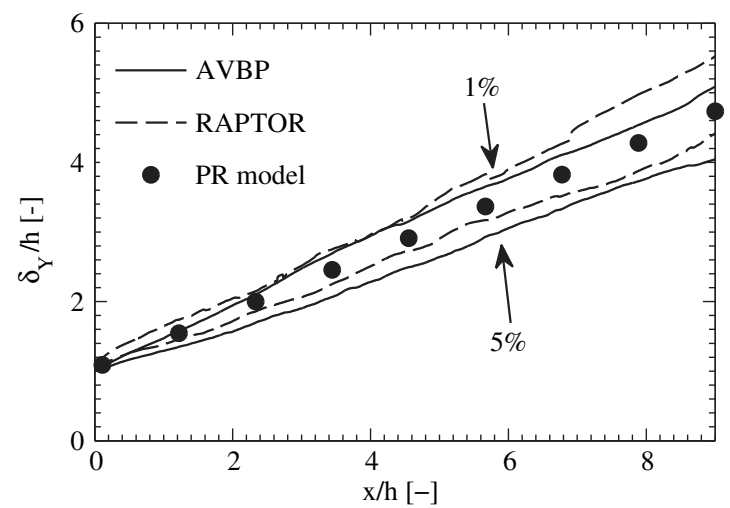

Fig. 10 Axial evolution of mixing-layer thicknesses.

In the work by Papamoschou and Roshko [74], a model was proposed to assess the spatial growth rate of variable-density mixing layers $\delta_{\text {vis }}^{\prime}$ as a function of the velocity and density ratios (contained in the definition of the convective velocity $U_{\text {conv }}$ ). This quantity is given by

$$
\delta_{\mathrm{vis}}^{\prime}=C \frac{\Delta U}{U_{\text {conv }}}
$$

where $C$ is a constant, $\Delta U$ is the velocity difference between the two streams, and $U_{\text {conv }}$ is the convection velocity defined by Eq. (16). As observed by Chehroudi [2], this model implies that the convection velocity of the largest eddies of the mixing layer depends on the density ratio of the two streams, whereas the opening angle of the mixing layer is only affected by the velocity difference $\Delta U$ in a reference frame moving at $U_{\text {conv }}$. Using the constant $C=0.17$, which enables one to retrieve the low-Mach-number mixing layers of Brown and Roshko [53] $\left(U_{\text {conv }}=39.6 \mathrm{~m} / \mathrm{s}\right.$ and $\Delta U=$ $U_{\mathrm{H}_{2}}-U_{\mathrm{O}_{2}}=95 \mathrm{~m} / \mathrm{s}$ ), we obtain $\delta_{\text {vis }}^{\prime}=0.41$.

In the work by Bernal and Roshko [83], the thickness of the mixing layer at a given axial location was defined as the distance between the location where $Y_{\mathrm{O}_{2}}=0.99$ and $Y_{\mathrm{O}_{2}}=0.01$ (1\% threshold). Here, we use this $1 \%$ threshold as well as a $5 \%$ threshold to show the sensitivity of the opening angle to this parameter. The axial evolution of the mixing-layer thicknesses for both AVBP and RAPTOR is plotted in Fig. 10. A linear regression of the spatial evolution of these thicknesses gives the spreading rates. The regression is performed past the wake region (for $x / h \geq 4$ only) in order to be comparable with a mixing-layer configuration. In AVBP, we obtain values of 0.44 and 0.35 for the 1 and $5 \%$ thresholds, respectively. In RAPTOR, we obtain values of 0.48 and 0.37 for the 1 and $5 \%$ thresholds, respectively. The growth rates are close to the 0.41 value obtained by the model for the variable-density mixing layers expressed in Eq. (19), which is plotted for comparison in Fig. 10 with the label 'PR model' (Papamoschou and Roshko). This model appears to provide a good estimate for the opening angle of two-dimensional supercritical mixing layers, even at a density ratio of $\rho_{\mathrm{O}_{2}} / \rho_{\mathrm{H}_{2}} \approx 80$, which is well beyond the range of density ratios explored experimentally $\left(\rho_{\mathrm{N}_{2}} / \rho_{\mathrm{He}}=1 / 7\right.$ to 7$)[\underline{53}, \underline{83}]$.

\section{Baseline Analysis of Instantaneous Fields}

Typical instantaneous fields obtained by the two solvers are presented in Fig. 11. Velocities, oxygen mass fraction, and density are shown. In both cases, the mixing layer is dominated by largescale vortical structures with characteristic sizes comparable to the momentum thickness (which is approximately $h$ ). In the velocity fields, three of these vortical structures are observed with a separation
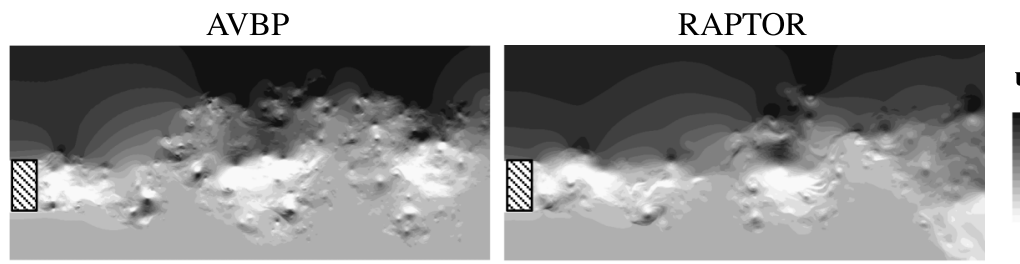

$\mathbf{u}[\mathrm{m} / \mathrm{s}]$
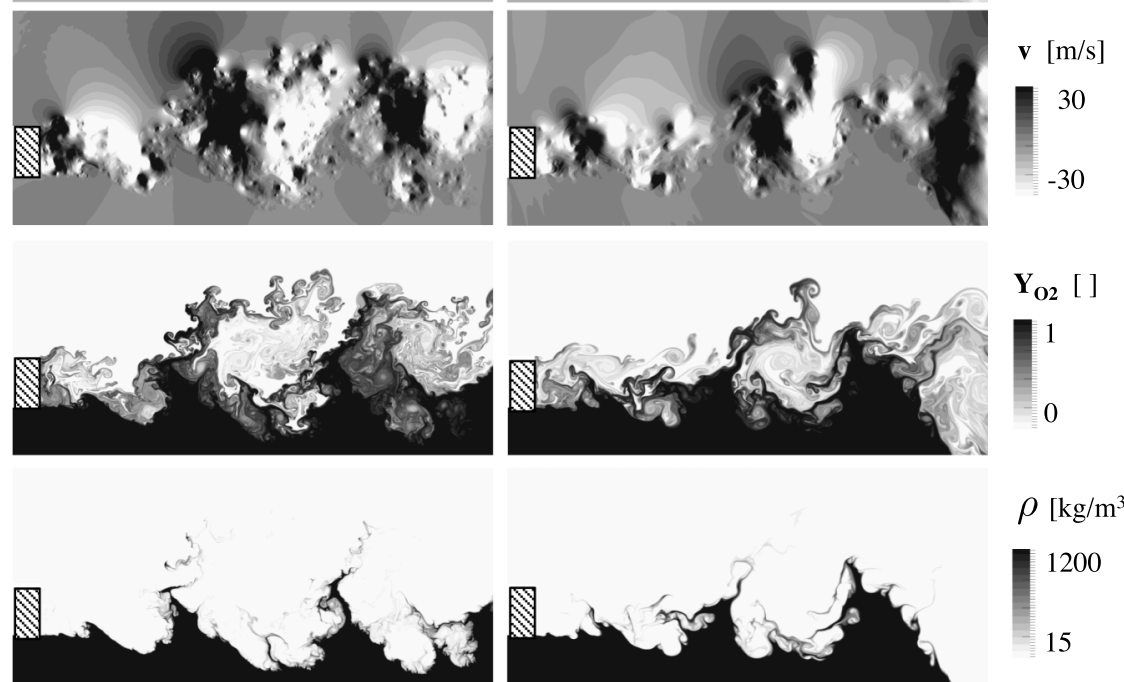

Fig. 11 Instantaneous flowfields in RAPTOR and AVBP. From top to bottom: axial velocity, transverse velocity, oxygen mass fraction, and density. 

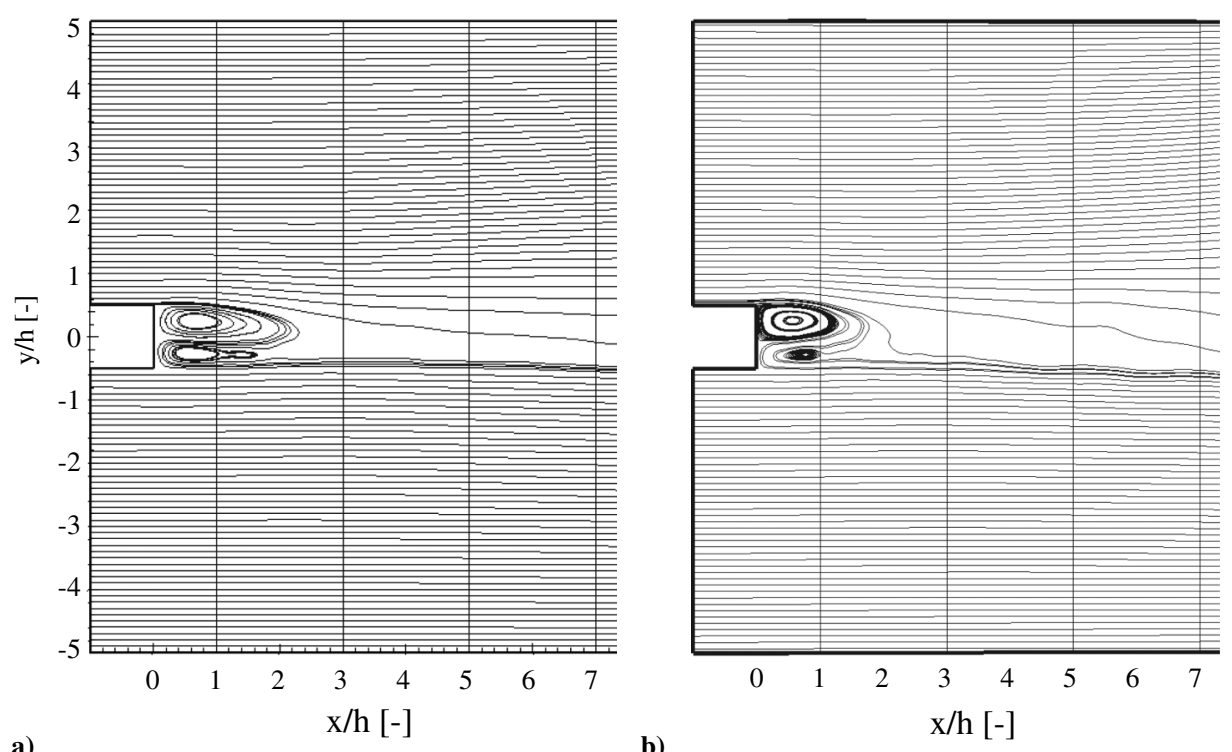

Fig. 12 Mean flowfield streamlines for a) AVBP and b) RAPTOR.

of approximately $5 h$. In the mean, their spatial wavelength is equal to $5 h$ [78]. Small-scale structures are also present in the mixing layer in both cases. This induces multiscale wrinkling of the oxygen and density fields. Waves are observed at the surface of the oxygen stream, with a wavelength comparable to the $5 h$ wavelength of the large vortical structures. These waves remind the "fingerlike" structures observed in many nonreacting supercritical experiments [1]. The nonlinearity associated with real-gas behavior is evident in the deviations between the mass fraction and density fields (see also Fig. 3). The steep density gradient induced by real-gas effects has a significant impact on turbulence, mainly through baroclinic-torque effects. Fluid particles with lower densities have less momentum and are more easily accelerated by pressure forces induced by vortices. Thus, when the gradients of density and pressure are misaligned, vorticity is generated and secondary instabilities are triggered [84]. In atmospheric-pressure variable-density flows, this mechanism leads to an early transition to turbulence [85-87]. This phenomenon is even stronger in the present flow, where density gradients are increased by real-gas thermodynamics.

\section{E. Time-Averaged One-Dimensional Profiles}

The streamlines obtained from the time-averaged velocity field are shown in Fig. 12. Overall, there is a very good agreement between the two solvers. There is a small deviation for the length and shape of the time-averaged recirculation zone immediately downstream of the lip. This is a sensitive feature of the flow that is influenced by the ensemble of vortices shed at the lip. Figure 12 also shows the location of the transverse 1-D cuts used in Figs. 13-16.

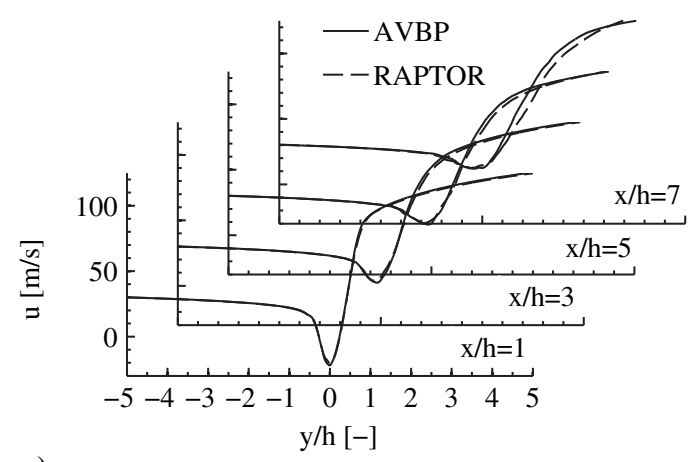

a)

Fig. 13 Transverse cuts of a) mean and b) rms axial velocity. These pro
Figure $13 \mathrm{a}$ shows the mean axial velocity. Very good agreement is observed. This figure shows that the flow transitions from a wake of the lip to a mixing layer as the velocity defect in the wake progressively disappears with axial distance.

Figure 13b shows the rms axial velocity. Good agreement is obtained between the two solvers. The peak rms velocity slowly decreases with axial distance from the lip, whereas the profiles broaden due to the development of turbulence. There is a strong asymmetry in the fluctuation profiles, and turbulence tends to develop on the light side of the mixing layer. This is due to the stabilizing effect of large density gradients on the oxygen side $[14, \underline{27}, \underline{88}, \underline{89}]$. Outside of the mixing layer and near the upper wall of the computational domain at $y / h=5$, the axial velocity fluctuations do not reach zero. A detailed observation of the mixing layer shows that these fluctuations are actually due to the penetration of fingerlike structures into the hydrogen stream. The presence of these largemomentum oxygen structures induces a reduction of the passage section for the hydrogen flow and creates intermittent accelerations on the hydrogen side, which result in velocity fluctuations. This is qualitatively observed on the instantaneous velocity and density field at the instant depicted in Fig. 11. In RAPTOR, fluctuations are slightly larger, which indicates a slightly larger penetration of the fingerlike structures into the hydrogen stream. This is consistent with the larger opening angle shown in Fig. 10.

Figure 14 a shows the mean transverse velocity. At $x / h=1$ and $x / h=3$, a negative transverse velocity indicates the presence of the recirculation zone in the wake of the lip. There is a small deviation between the two solvers at $x / h=1$, which is related to the small

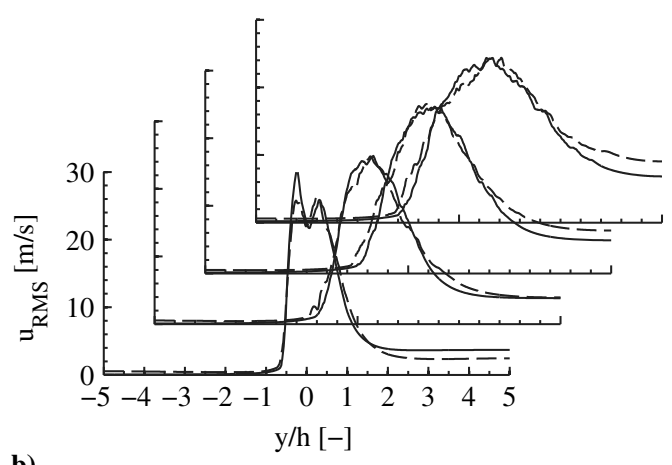

b) 


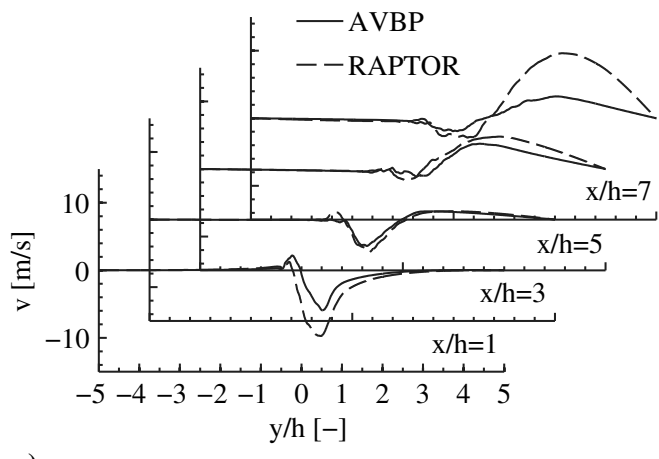

a)

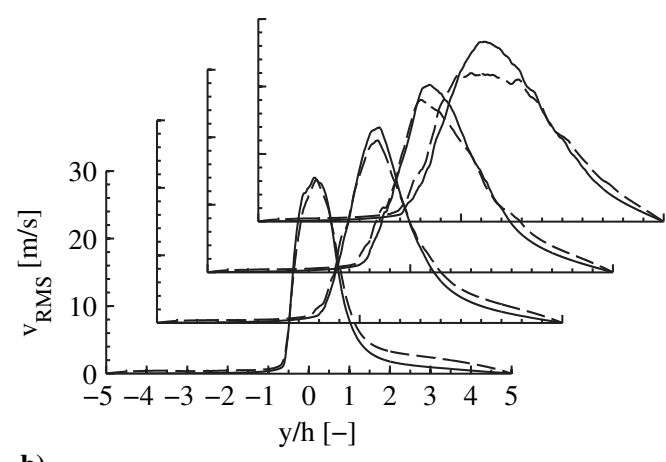

b)

Fig. 14 Transverse cuts of a) mean and b) rms transverse velocity. These profiles are also provided as supplemental data.

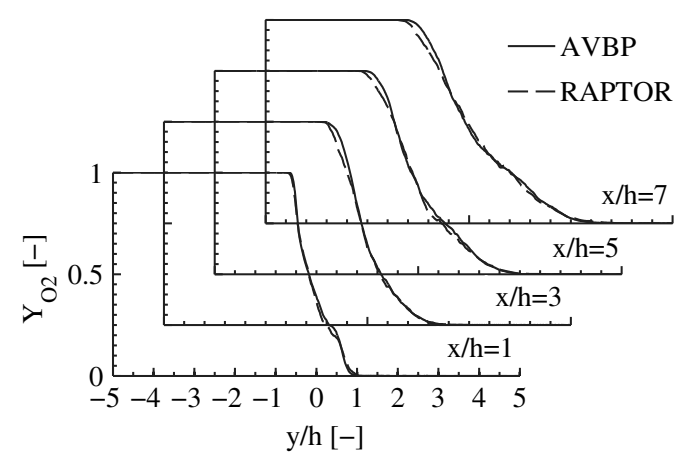

a)

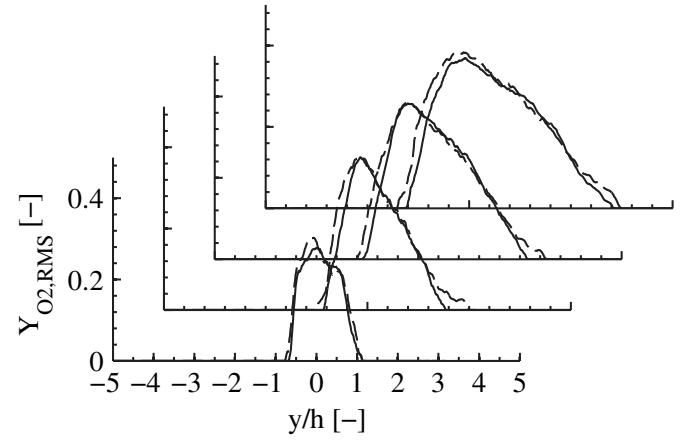

b)

Fig. 15 Transverse cuts of a) mean and b) rms oxygen mass fraction. These profiles are also provided as supplemental data.

deviations in the length and shape of the recirculation zone immediately downstream of the lip, as observed in Fig. 12.

At $x / h=5$, both solvers indicate that, in the mean, a small upward velocity is present on the hydrogen side. This is related to the rise of fingerlike structures in the hydrogen stream, inducing an upward deviation of the hydrogen stream. At $x / h=7$, a larger transverse velocity is observed in RAPTOR, which also tends to indicate a larger penetration of fingerlike structures in the hydrogen stream.

Figure $14 \mathrm{~b}$ shows the rms transverse velocity. Good agreement is obtained between the two solvers. The peak rms velocity slowly decreases with axial distance from the lip, whereas the profiles broaden due to the development of turbulence. The peak rms velocity in the vicinity of $y / h=0$ is slightly smaller in RAPTOR than in AVBP. On the hydrogen side, fluctuations are slightly larger in RAPTOR, which once again appears consistent with a larger penetration of fingerlike structures in the hydrogen stream.

Figure 15a shows the mean profiles of oxygen mass fraction. At $x / h=1$, the profile of oxygen mass fraction has a nonclassical shape with a steep slope in the vicinity of $y / h=0.5$, which is in the immediate wake of the hydrogen vorticity layer. Both solvers predict this particular feature. Then, from $x / h=3$ to $x / h=7$, the mean profile of oxygen mass fraction thickens due to turbulent mixing. The agreement between the two solvers is excellent at every location.

Figure $15 \mathrm{~b}$ shows the rms profiles of oxygen mass fraction. In the recirculation zone at $x / h=1$, the scalar fluctuations have a flat profile with a plateau located at $Y_{\mathrm{O}_{2}, \mathrm{RMS}}=0.3$. Both solvers predict this feature. At $x / h=3$, the maximum fluctuation increases to $Y_{\mathrm{O}_{2}, \text { RMS }}=0.4$, and the profile broadens on the hydrogen side up to $y / h=2$. On the oxygen side, fluctuations only reach $y / h=-1$. This asymmetry is accentuated further downstream at $x / h=5$ and $x / h=7$. At $x / h=7$, the fluctuations reach $x / h=-1.5$ on the oxygen side, whereas they reach $x / h=3.5$ on the hydrogen side, which clearly shows the asymmetry. The mean and rms of the oxygen mass fraction are in excellent agreement and capture the growth of the mixing-layer thickness due to turbulent mixing.

Figures $16 \mathrm{a}$ and $16 \mathrm{~b}$ show the mean and rms of temperature profiles. In comparison with velocity and species profiles, the temperature profiles show larger deviations. The temperature profiles in AVBP are steeper than in RAPTOR. The fluctuations show similar peak values but spread more toward the light hydrogen side in

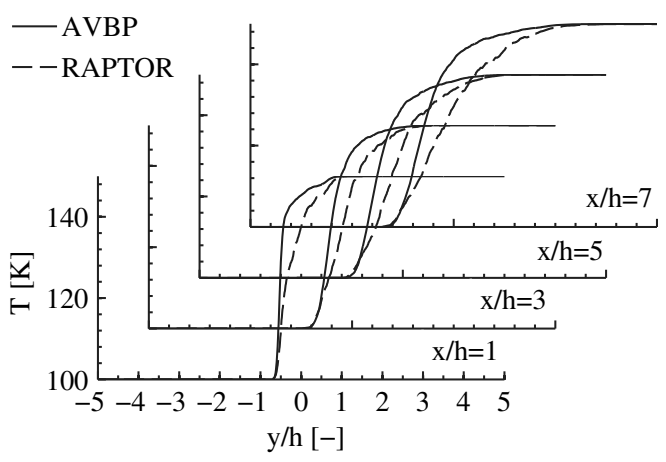

a)

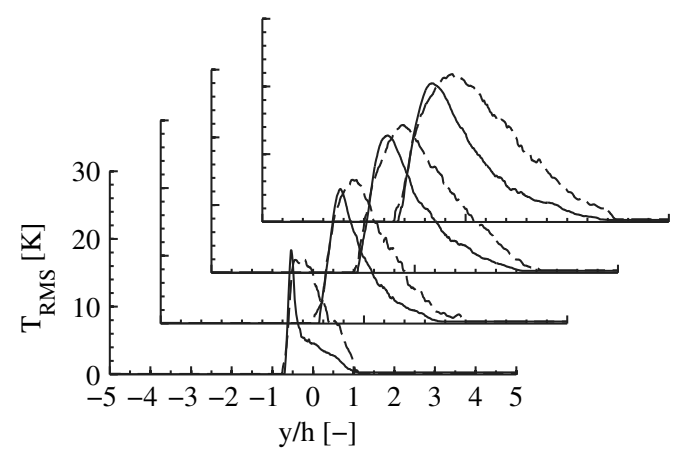

b)

Fig. 16 Transverse cuts of a) mean and b) rms temperature. These profiles are also provided as supplemental data. 


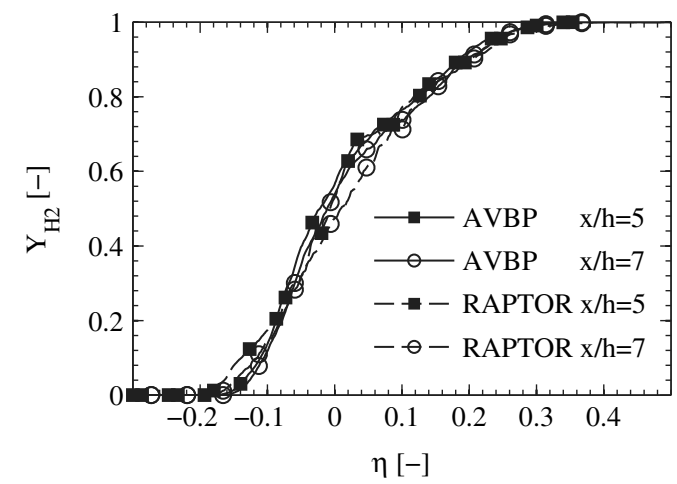

a)

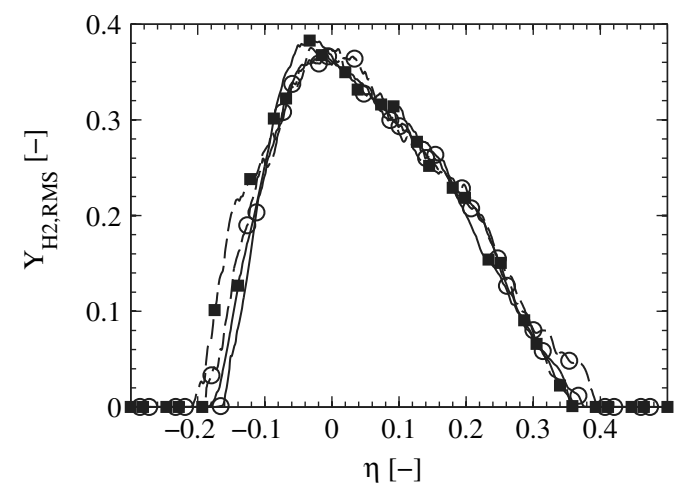

b)

Fig. 17 Mean and rms hydrogen mass fraction versus similarity variable $\eta=y /\left(x-x_{0}\right):$ a) mean hydrogen mass fraction and b) rms fluctuations of hydrogen mass fraction.

RAPTOR. In RAPTOR, the spatial extent of the temperature and mass fraction fluctuations are approximately similar; whereas in AVBP, the spatial extent of the temperature fluctuations are narrower than the mass fraction fluctuations. This difference could come from the differences in the Schmidt numbers used between AVBP and RAPTOR (see Fig. 4c). Because of the large Reynolds number, preferential diffusion effects are likely to be small. This deviation could also be induced by the difference in the numerical methodologies used in AVBP and RAPTOR. In AVBP, the energy correction method used to prevent spurious acoustic wave generation could impact the temperature field. Conversely, the absence of specific treatment of real-gas thermodynamics in the stabilization method in RAPTOR could also impact the turbulent field.

Overall, good quantitative agreement is obtained between the two solvers for most turbulence quantities of interest, which lends confidence to the physical accuracy of the results. The database of mean and rms profiles is available as supplemental data in Appendix A.

\section{F. Self-Similarity of the Supercritical Mixing Layer}

Self-similarity is a feature of turbulent flows that is widely used to study turbulent jets (see [90] for instance). Self-similarity implies that it is possible to collapse turbulence profiles at different axial location using a similarity variable $\eta$. To investigate whether self-similarity is observed in this flow, the mean and rms of hydrogen mass fraction are presented in Fig. 17 as a function of $\eta=y /\left(x-x_{0}\right)$, where $x_{0}$ is the virtual origin of the mixing layer. As in the work by Bernal and Roshko [83], linear regression of the mixing-layer thickness is employed based on the 1\% mass fraction threshold (see Fig. 10) to determine the virtual origin. It was found that $x_{0}=-2.5 h$ for $\overline{\mathrm{AVBP}}$ and $x_{0}=-2.3 h$ for RAPTOR. As the wake component of the flow disappears and the turbulent mixing layer develops, self-similar scalar profiles are observed, even in the near field. This rapid transition to turbulence is due to the large Reynolds number of the present flow and real-gas effects. The steep density gradients generated by the nonlinearity of the equation of state (see Fig. 3) enhance baroclinic torque, which in turn generates vorticity. The results presented in Fig. 17 are qualitatively comparable to the profiles obtained in the self-similar region of a variable-density $\mathrm{HE} / \mathrm{N}_{2}$ plane mixing layer [83] (figures 16 and 17 in work by Bernal and Roshko [83], where $\rho_{\mathrm{N}_{2}} / \rho_{\mathrm{He}}=7$ and $\left.U_{\mathrm{N}_{2}} / U_{\mathrm{He}}=0.38\right)$. A similar asymmetry in the profiles of the mean and rms concentration is observed, and fluctuations are more largely present in the light stream $(\eta>0)$.

\section{Conclusions}

A benchmark for CFD simulations of high-pressure highReynolds-number supercritical flows with large density gradients has been established. This type of flow is encountered in many propulsion and power devices, such as liquid rocket engines, diesel engines, and modern gas turbines. The challenge for solver validation at these conditions is the absence of detailed experimental data. Additionally, high-Reynolds-number flows are still out of reach for three-dimensional direct numerical simulation, even with the largest supercomputers available today. The approach selected in the present study relies on two-dimensional direct numerical simulation.

The benchmark case considered is a mixing layer forming downstream of an injector lip separating a stream of dense oxygen from a stream of light hydrogen. This case has characteristic flow features that can be found in rocket engines with a Reynolds number in the range of $10^{5}$, an operating pressure of $10 \mathrm{MPa}$, and a density ratio between the oxidizer and the fuel streams of 80 . The overall configuration and boundary conditions were selected to facilitate its reproducibility by other groups. Simple and controlled boundary conditions have been defined to make detailed analysis of statistics computationally affordable.

The confidence in the results has been established on two aspects. First, two state-of-the-art solvers have been used to perform computations under identical conditions. Both are based on advanced theoretical frameworks for real fluid thermodynamics, but they use different numerical methodologies. These two solvers provide very comparable statistics in the present case. Second, a grid-convergence study has been conducted to determine the resolution, beyond which the turbulence statistics are no longer dependent on grid spacing. At the resolution chosen to build the database, the quantities of interest are not impacted by the numerical approaches, which lends confidence that the results only depend on the physics.

Transverse profiles of the mean and rms velocity, oxygen mass fraction, and temperature are provided at several axial locations, and self-similarity has been identified. Real-gas effects have also been observed. The real-gas equation of state induces strong nonlinear variations of density, which create strong density gradients in the flowfield. These strong density gradients create an asymmetry in the transverse profiles of rms velocity, and turbulence preferably develops on the light side of the mixing layer. Although some similarities with variable-density mixing layers are observed, the early transition to self-similarity might be characteristic of supercritical flows with large density ratios due to enhanced baroclinic-torque effects.

The established database can be used for solver benchmarking at conditions relevant to many propulsion and power systems. It can also serve as a reference point to further investigate the impact of design parameters on turbulent mixing, such as thermodynamic quantities, dynamics, and geometrical aspects. Accurate turbulence closures for large-eddy simulation of high-Reynolds-number flows with large density gradients can also be derived and benchmarked using the present work.

\section{Appendix A: Database}

The mean and rms profiles presented in Sec. IV.E are available as supplemental material. The results from AVBP and RAPTOR are 
labelled avbp_xn.txt and raptor_xn.txt, respectively, where $n$ indicates the axial location of the transverse cut. For instance avbp_x1.txt corresponds to the transverse cut located at $x / h=1$, between $y / h=-5$ and $y / h=5$. A header is provided at the beginning of each file, which clearly indicates the content of each column. The variables are provided in Système International units, as plotted in Figs. 13-16.

\section{Appendix B: Relative Computational Cost}

Table B1 summarizes the computational cost involved in the gridconvergence study conducted with AVBP in Sec. IV.B. These simulations have been conducted on the JADE supercomputer at Centre Informatique National de l'Enseignement Supérieur (Intel quadcore at $2.8 \mathrm{GHz}$ ), where the efficiency of AVBP is $15 \times 10^{-6} \mathrm{~s}$ per iteration and per cell. Section IV.A shows that a time-averaging duration of $1.83 \times 10^{-3} \mathrm{~s}$ is sufficient to obtain converged statistics. The time steps then determine the number of iterations. To assess the cost of analogous three-dimensional (3-D) simulations, the spanwise extent must be chosen. Studies have shown that a spanwise extent on the order of $10 \mathrm{~h}$ enables one to decorrelate turbulent fluctuations and prevent confinement [91,92]. With a $10 \mathrm{~h}$ spanwise extent, the resulting number of cells for the $h 250$ and $h 500$ simulations would be 8.5 and 68.5 billion cells. The largest simulations of turbulent combustion that are currently performed on supercomputers are typically in the range of $1-10$ billion cells $[93,94]$. Thus, the benchmark would be inaccessible to most of the $\mathrm{C} \overline{\mathrm{FD}}$ community if a three-dimensional computational domain was chosen. The CPU costs associated with obtaining converged statistics in three dimensions are also beyond reach, since one billion CPU hours would be required to perform the $h 500$ simulation. This is the main motivation for using a two-dimensional computational domain. The quick turnaround time of the simulations facilitates CFD solver benchmarking.

\section{Appendix C: Scale Separation}

Figure $\underline{8}$ shows that, for the finest grid $(h 500)$, the frequency that corresponds to the peak of PSD is $f=8000 \mathrm{~Hz}$. The frequency for which the slope of the spectrum changes from $-5 / 3$ to -3 is $f=500 \times 10^{3} \mathrm{~Hz}$. The scale separation is thus on the order of 50 . This would correspond to a turbulence Reynolds number of $R e_{t}=50^{4 / 3}=185$ in a fully developed three-dimensional turbulent flow. However, the present configuration is a transition to turbulence, where turbulence production and dissipation are not at equilibrium, and scale separation is not as large as in fully developed turbulence. The turbulence Reynolds number can be assessed directly:

$$
R e_{t}=u^{\prime} l_{t} / \nu=40 \times 10^{3}
$$

where $u^{\prime}=25 \mathrm{~m} / \mathrm{s}$ is the peak velocity fluctuations (see Fig. 13); $\nu=3 \times 10^{-7} \mathrm{~m}^{2}$ is the median viscosity between stream values; and $l_{t}=h$ is the integral scale, which is imposed by the momentum thickness at the inlet (see Sec. II.B). This large Reynolds number would induce a scale separation of 3000 instead of 50 in a fully developed flow region. Studies of turbulent jets show that turbulence is fully developed in the far field only, where $x / d$ is in the range of $30-100 d$ [90], whereas our computational domain is limited to the near field and is two-dimensional.

\section{Acknowledgments}

Support for this research was provided jointly by the U.S. Department of Energy Office of Science, Basic Energy Sciences program; and the Office of Energy Efficiency and Renewable Energy, Vehicle Technologies (VT) program, under grant numbers KC0301020 and VT0401000. Support for this research was also provided by Snecma, the prime contractor for the European launcher Ariane 5 cryogenic propulsion systems; and Centre National d'Etudes Spatiales, the government agency responsible for shaping and implementing France's space policy in Europe. Their support is gratefully acknowledged. The RAPTOR simulations used resources of the Oak Ridge Leadership Computing Facility at the Oak Ridge National Laboratory, which is supported by the Office of Science of the U.S. Department of Energy under contract no. DE-AC0500OR22725. The AVBP simulations used resources of the highperformance computing resources of Centre Informatique National de l'Enseignement Supérieur under the allocation 2011c2011025082 made by Grand Equipement National de Calcul Intensif.

\section{References}

[1] Oschwald, M., Smith, J. J., Branam, R., Hussong, J., Schik, A., Chehroudi, B., and Talley, D., "Injection of Fluids into Supercritical Environments," Combustion Science and Technology, Vol. 53, Nos. 11, 2006, pp. 49-100.

doi:10.1080/00102200500292464

[2] Chehroudi, B., "Recent Experimental Efforts on High-Pressure Supercritical Injection for Liquid Rockets and Their Implications," International Journal of Aerospace Engineering, Vol. 2012, 2012, pp. $1-31$.

doi: $10.1155 / 2012 / 121802$

[3] Mayer, W., Tellar, J., Branam, R., Schneider, G., and Hussong, J., "Raman Measurement of Cryogenic Injection at Supercritical Pressure," Heat and Mass Transfer, Vol. 39, Nos. 8-9, 2003, pp. 709-719. doi:10.1007/s00231-002-0315-X

[4] Oschwald, M., "Supercritical Nitrogen Free Jet Investigated by Spontaneous Raman Scattering," Experiments in Fluids, Vol. 27, No. 6, 1999, pp. 497-506. doi: $10.1007 / \mathrm{s} 003480050374$

[5] Oschwald, M., and Micci, M., "Spreading Angle and Centerline Variation of Density of Supercritical Nitrogen Jets," Atomization and Sprays, Vol. 12, Nos. 1-3, 2002, pp. 91-106. doi:10.1615/AtomizSpr.v12.1123

[6] Chehroudi, B., Cohn, R., and Talley, D., "Cryogenic Shear Layers: Experiments and Phenomenological Modeling of the Initial Growth Rate Under Subcritical and Supercritical Conditions," International Journal of Heat and Fluid Flow, Vol. 23, No. 5, Oct. 2002, pp. 554-563. doi:10.1016/S0142-727X(02)00151-0

[7] Davis, D., and Chehroudi, B., "Measurements in an Acoustically Driven Coaxial Jet Under Sub-, Near-, and Supercritical Conditions," Journal of Propulsion and Power, Vol. 23, No. 2, 2007, pp. 364-374. doi:10.2514/1.19340

[8] Eroglu, H., Chigier, N., and Farago, Z., "Coaxial Atomizer Liquid Intact Lengths," Physics of Fluids A: Fluid Dynamics, Vol. 3, No. 2, 1991, p. 303.

doi:10.1063/1.858139

[9] Leyva, I., Chehroudi, B., and Talley, D., "Dark Core Analysis of Coaxial Injectors at Sub-, Near-, and Supercritical Conditions in a Transverse Acoustic Field," 43rd AIAA Joint Propulsion Conference and Exhibit, AIAA Paper 2007-5456, 2007.

[10] Locke, J., Pal, S., Woodward, R., and Santoro, R., "High Speed Visualization of LOX/GH2 Rocket Injector Flowfield: Hot-Fire and Cold-Flow Experiments," 46th AIAA/ASME/SAE/ASEE Joint Propulsion Conference and Exhibit, AIAA Paper 2010-7145, 2010.

Table B1 Computational cost for the convergence study performed in Sec. IV.B and for an analogous study in 3-D

\begin{tabular}{lcccccc}
\hline \hline & $\begin{array}{c}\text { Time step, } \\
10^{9} \mathrm{~s}\end{array}$ & $\begin{array}{c}\text { Number of } \\
\text { iterations, } 10^{6}\end{array}$ & $\begin{array}{c}\text { Number of } \\
\text { cells in 2-D, } 10^{6}\end{array}$ & $\begin{array}{c}\text { Number of } \\
\text { cells in 3-D, } 10^{9}\end{array}$ & $\begin{array}{c}\text { 2-D cost, } 10^{3} \text { CPU } \\
\text { hours }\end{array}$ & $\begin{array}{c}\text { 3-D cost, 10 } \mathrm{CPU} \\
\text { hours }\end{array}$ \\
\hline$h 30$ & 7.5 & 0.2 & 0.04 & 0.012 & 0.03 & 0.01 \\
$h 100$ & 2.5 & 0.7 & 0.55 & 0.55 & 1.6 & 1.6 \\
$h 250$ & 1.0 & 1.8 & 3.4 & 8.5 & 26 & 63 \\
$h 500$ & 0.5 & 3.7 & 13.7 & 68.5 & 210 & 1000 \\
\hline \hline
\end{tabular}


[11] Roy, A., Segal, C., and Joly, C., "Spreading Angle and Core Length Analysis of Supercritical Jets," AIAA Journal, Vol. 51, No. 8, 2013, pp. 2009-2014. doi:10.2514/1.J052415

[12] Bellan, J., "Supercritical (and Subcritical) Fluid Behavior and Modeling: Drops, Streams, Shear and Mixing Layers, Jets and Sprays," Progress in Energy and Combustion Science, Vol. 26, Nos. 4-6, 2000, pp. 329-366. doi:10.1016/S0360-1285(00)00008-3

[13] Miller, R. S., Harstad, K. G., and Bellan, J., "Direct Numerical Simulations of Supercritical Fluid Mixing Layers Applied to HeptaneNitrogen," Journal of Fluid Mechanics, Vol. 436, June 2001, pp. 1-39. doi:10.1017/S0022112001003895

[14] Okong'o, N., and Bellan, J., "Direct Numerical Simulation of a Transitional Supercritical Binary Mixing Layer: Heptane and Nitrogen," Journal of Fluid Mechanics, Vol. 664, Aug. 2002, pp. 1-34. doi:10.1017/S0022112002008480

[15] Bellan, J., "Theory, Modeling and Analysis of Turbulent Supercritical Mixing," Combustion Science and Technology, Vol. 53, Nos. 1-3, 2006, pp. 253-281. doi:10.1080/00102200500292241

[16] Foster, J., and Miller, R. S., "A Priori Analysis of Subgrid Mass Diffusion Vectors in High Pressure Turbulent Hydrogen/Oxygen Reacting Shear Layer Flames," Physics of Fluids, Vol. 24, No. 7, 2012, Paper 75114. doi:10.1063/1.4739065

[17] Selle, L. C., Okong'o, N. A., Bellan, J., and Harstad, K. G., "Modelling of Subgrid-Scale Phenomena in Supercritical Transitional Mixing Layers: An a Priori Study," Journal of Fluid Mechanics, Vol. 593, Dec. 2007, pp. 57-91. doi:10.1017/S0022112007008075

[18] Taskinoglu, E. S., and Bellan, J., "A Posteriori Study Using a DNS Database Describing Fluid Disintegration and Binary-Species Mixing Under Supercritical Pressure: Heptane and Nitrogen," Journal of Fluid Mechanics, Vol. 645, No. 1, 2010, pp. 211-254. doi:10.1017/S0022112009992606

[19] Oefelein, J., and Yang, V., "Modeling High-Pressure Mixing and Combustion Processes in Liquid Rocket Engines," Journal of Propulsion and Power, Vol. 14, No. 5, 1998, pp. 843-857. doi: $10.2514 / 2.5349$

[20] Oefelein, J., "Thermophysical Characteristics of Shear-Coaxial LOXH2 Flames at Supercritical Pressure," Proceedings of the Combustion Institute, Vol. 30, No. 2, 2005, pp. 2929-2937. doi:10.1016/j.proci.2004.08.212

[21] Oefelein, J., "Mixing and Combustion of Cryogenic Oxygen-Hydrogen Shear-Coaxial Jet Flames at Supercritical Pressure," Combustion Science and Technology, Vol. 53, Nos. 1-3, 2006, pp. 229-252. doi:10.1080/00102200500325322

[22] Zong, N., Meng, H., Hsieh, S.-Y., and Yang, V., "A Numerical Study of Cryogenic Fluid Injection and Mixing Under Supercritical Conditions," Physics of Fluids, Vol. 16, No. 12, Dec. 2004, pp. 4248-4261. doi:10.1063/1.1795011

[23] Zong, N., and Yang, V., "Cryogenic Fluid Jets and Mixing Layers in Transcritical and Supercritical Environments," Combustion Science and Technology, Vol. 53, Nos. 1-3, 2006, pp. 193-227. doi: $10.1080 / 00102200500287613$

[24] Zong, N., and Yang, V., "Near-Field Flow and Flame Dynamics of LOX/ Methane Shear-Coaxial Injector Under Supercritical Conditions," Proceedings of the Combustion Institute, Vol. 31, No. 2, 2007, pp. 2309-2317. doi:10.1016/j.proci.2006.08.106

[25] Masquelet, M., Menon, S., Jin, Y., and Friedrich, R., "Simulation of Unsteady Combustion in a LOX-GH2 Fueled Rocket Engine," Aerospace Science and Technology, Vol. 13, No. 8, 2009, pp. 466-474. doi:10.1016/j.ast.2009.07.005

[26] Schmitt, T., Selle, L., Cuenot, B., and Poinsot, T., "Large-Eddy Simulation of Transcritical Flows," Comptes Rendus Mécanique, Vol. 337, Nos. 6-7, 2009, pp. 528-538.

[27] Schmitt, T., Selle, L., Ruiz, A., and Cuenot, B., "Large-Eddy Simulation of Supercritical-Pressure Round Jets," AIAA Journal, Vol. 48, No. 9, Sept. 2010, pp. 2133-2144. doi:10.2514/1.J050288

[28] Schmitt, T., Méry, Y., Boileau, M., and Candel, S., "Large-Eddy Simulation of Oxygen/Methane Flames under Transcritical Conditions," Proceedings of the Combustion Institute, Vol. 33, No. 1, 2011, pp. $1383-1390$. doi:10.1016/j.proci.2010.07.036

[29] Schmitt, T., Rodriguez, J., Leyva, I., and Candel, S., "Experiments and Numerical Simulation of Mixing under Supercritical Conditions,"
Physics of Fluids, Vol. 24, No. 5, 2012, Paper 055104. doi:10.1063/1.3701374

[30] Terashima, H., Kawai, S., and Yamanishi, N., "High-Resolution Numerical Method for Supercritical Flows with Large Density Variations," AIAA Journal, Vol. 49, No. 12, 2011, pp. 2658-2672. doi:10.2514/1.J051079

[31] Terashima, H., and Koshi, M., "Approach for Simulating Gas-LiquidLike Flows Under Supercritical Pressures Using a High-Order Central Differencing Scheme," Journal of Computational Physics, Vol. 231, No. 20, 2012, pp. 6907-6923. doi:10.1016/j.jcp.2012.06.021

[32] Petit, X., Ribert, G., Lartigue, G., and Domingo, P., "Large-Eddy Simulation of Supercritical Fluid Injection," Journal of Supercritical Fluids, Vol. 84, Dec. 2013, pp. 61-73. doi:10.1016/j.supflu.2013.09.011

[33] Chehroudi, B., Talley, D., and Coy, E., "Visual Characteristics and Initial Growth Rate of Round Cryogenic Jets at Subcritical and Supercritical Pressures," Physics of Fluids, Vol. 14, No. 2, Feb. 2002, pp. $850-861$ doi:10.1063/1.1430735

[34] Villermaux, E., and Rehab, H., "Mixing in Coaxial Jets," Journal of Fluid Mechanics, Vol. 425, No. 1, 2000, pp. 161-185. doi:10.1017/S002211200000210X

[35] Selle, L., Lartigue, G., Poinsot, T., Koch, R., Schildmacher, K.-U., Krebs, W., Prade, B., Kaufmann, P., and Veynante, D., "Compressible Large-Eddy Simulation of Turbulent Combustion in Complex Geometry on Unstructured Meshes," Combustion and Flame, Vol. 137, No. 4, 2004, pp. 489-505. doi:10.1016/j.combustflame.2004.03.008

[36] Roux, S., Lartigue, G., Poinsot, T., Meier, U., and Bérat, C., "Studies of Mean and Unsteady Flow in a Swirled Combustor Using Experiments, Acoustic Analysis and Large Eddy Simulations," Combustion and Flame, Vol. 141, Nos. 1-2, 2005, pp. 40-54. doi:10.1016/j.combustflame.2004.12.007

[37] Wolf, P., Staffelbach, G., Gicquel, L. Y., Müller, J.-D., and Poinsot, T., "Acoustic and Large Eddy Simulation Studies of Azimuthal Modes in Annular Combustion Chambers," Combustion and Flame, Vol. 159, No. 11, 2012, pp. 3398-3413. doi:10.1016/i.combustflame.2012.06.016

[38] Vermorel, O., Richard, S., Colin, O., Angelberger, C., Benkenida, A., and Veynante, D., "Towards the Understanding of Cyclic Variability in a Spark Ignited Engine Using Multi-Cycle LES," Combustion and Flame, Vol. 156, No. 8, 2009, pp. 1525-1541. doi:10.1016/j.combustflame.2009.04.007

[39] Enaux, B., Granet, V., Vermorel, O., Lacour, C., Pera, C., Angelberger, C., and Poinsot, T., "LES and Experimental Study of Cycle-to-Cycle Variations in a Spark Ignition Engine," Proceedings of the Combustion Institute, Vol. 33, No. 2, 2011, pp. 3115-3122. doi:10.1016/j.proci.2010.07.038

[40] Roux, A., Gicquel, L. Y. M., Reichstadt, S., Bertier, N., Staffelbach, G., Vuillot, F., and Poinsot, T., "Analysis of Unsteady Reacting Flows and Impact of Chemistry Description in Large Eddy Simulations of SideDump Ramjet Combustors," Combustion and Flame, Vol. 157, No. 1, 2010, pp. 176-191. doi:10.1016/j.combustflame.2009.09.020

[41] Gourdain, N., Gicquel, L., Montagnac, M., Vermorel, O., Gazaix, M., Staffelbach, G., García, M., Boussuge, J.-F., and Poinsot, T., "High Performance Parallel Computing of Flows in Complex GeometriesPart 1: Methods," Computational Science and Discovery, Vol. 2, Nov. 2009, Paper 015003.

[42] Gourdain, N., Gicquel, L., Staffelbach, G., Vermorel, O., Duchaine, F., Boussuge, J.-F., and Poinsot, T., "High Performance Parallel Computing of Flows in Complex Geometries-Part 2: Applications," Computational Science and Discovery, Vol. 2, Nov. 2009, Paper 015004.

[43] Hakim, L., Ruiz, A., Schmitt, T., Boileau, M., Staffelbach, G., Ducruix, S., Cuenot, B., and Candel, S., "Large Eddy Simulations of Multiple Transcritical Coaxial Flames Submitted to a High-Frequency Transverse Acoustic Modulation," Proceedings of the Combustion Institute, Vol. 35, No. 2, 2014, pp. 1461-1468. doi:10.1016/j.proci.2014.05.142

[44] Oefelein, J., and Yang, V., "Special Issue: Supercritical Fluid Transport and Combustion," Combustion Science and Technology, Vol. 53, Nos. 1-3, 2006, pp. i-iii. doi: $10.1080 / 00102200500394377$

[45] Hu, B., Musculus, M. P., and Oefelein, J. C., "The Influence of LargeScale Structures on Entrainment in a Decelerating Transient Turbulent Jet Revealed by Large Eddy Simulation," Physics of Fluids, Vol. 24, No. 4, 2012, Paper 045106. doi: $10.1063 / 1.3702901$ 
[46] Lacaze, G., Misdariis, A., Ruiz, A., and Oefelein, J. C., "Analysis of High-Pressure Diesel Fuel Injection Processes Using LES with RealFluid Thermodynamics and Transport," Proceedings of the Combustion Institute, Vol. 35, No. 2, 2014, pp. 1603-1611. doi:10.1016/j.proci.2014.06.072

[47] Poinsot, T., and Veynante, D., Theoretical and Numerical Combustion, 3rd ed., 2005, pp. 16-17, http://elearning.cerfacs.fr/combustion/ onlinePoinsotBook/buythirdedition/index.php.

[48] Meng, H., and Yang, V., "A Unified Treatment of General Fluid Thermodynamics and Its Application to a Preconditioning Scheme," Journal of Computational Physics, Vol. 189, No. 1, July 2003, pp. 277 304. doi:10.1016/S0021-9991(03)00211-0

[49] Peng, D.-Y., and Robinson, D. B., "A New Two-Constant Equation of State," Industrial and Engineering Chemistry Fundamentals, Vol. 15, No. 1, Feb. 1976, pp. 59-64 doi:10.1021/i160057a011

[50] Soave, G., "Equilibrium Constants from a Modified Redlich-Kwong Equation of State," Chemical Engineering Science, Vol. 27, No. 6, 1972, pp. 1197-1203. doi:10.1016/0009-2509(72)80096-4

[51] Lemmon, E., McLinden, M., and Friend, D., "NIST Standard Reference Database Number 69," NIST Chemistry WebBook, National Inst. of Standards and Technology, Gaithersburg, MD, 2015, http://webbook. nist.gov/chemistry/fluid/ [retrieved September 2014].

[52] Benedict, M., Webb, G., and Rubin, L., "An Empirical Equation for Thermodynamic Properties of Light Hydrocarbons and Their Mixtures II. Mixtures of Methane, Ethane, Propane, and n-Butane," Journal of Chemical Physics, Vol. 10, No. 12, 1942, pp. 747-758. doi:10.1063/1.1723658

[53] Brown, G. L., and Roshko, A., "On Density Effects and Large Structure in Turbulent Mixing Layers," Journal of Fluid Mechanics, Vol. 64, No. 4, 1974, pp. 775-816. doi:10.1017/S002211207400190X

[54] Hannoun, I., Fernando, H., and List, E., "Turbulence Structure near a Sharp Density Interface," Journal of Fluid Mechanics, Vol. 189, No. 1, 1988, pp. 189-209. doi:10.1017/S0022112088000965

[55] Chung, T. H., Lee, L. L., and Starling, K. E., "Applications of Kinetic Gas Theories and Multiparameter Correlation for Prediction of Dilute Gas Viscosity and Thermal Conductivity," Industrial and Engineering Chemistry Fundamentals, Vol. 23, No. 1, 1984, pp. 8-13. doi:10.1021/i100013a002

[56] Chung, T., Ajlan, M., Lee, L., and Starling, K., "Generalized Multiparameter Correlation for Nonpolar and Polar Fluid Transport Properties," Industrial and Engineering Chemistry Research, Vol. 27, No. 4, 1988, pp. 671-679. doi:10.1021/ie00076a024

[57] Matuszewski, L., "Modélisation et Simulation Numérique des Phénomènes de Combustion en Régime Supercritique," Ph.D. Thesis, Ecole Polytechnique, Route de Saclay, Palaiseau, France, March 2011.

[58] Ely, J., and Hanley, H. J. M., "Prediction of Transport Properties. 1. Viscosity of Fluids and Mixtures," Industrial and Engineering Chemistry Fundamentals, Vol. 20, No. 4, 1981, pp. 323-332. doi:10.1021/i100004a004

[59] Ely, J., and Hanley, H. J. M., "Prediction of Transport Properties. 2. Thermal Conductivity of Pure Fluids and Mixtures," Industrial and Engineering Chemistry Fundamentals, Vol. 22, No. 1, 1983, pp. 90-97. doi:10.1021/i100009a016

[60] Hirschfelder, J. O., Curtiss, C. F., and Bird, R. B., Molecular Theory of Gases and Liquids, Wiley, New York, 1954, pp. 514-610, Chap. 8

[61] Bird, R., Stewart, W., and Lighfoot, E., Transport Phenomena, Wiley, New York, 1960, pp. 513-542.

[62] Takahashi, S., "Preparation of a Generalized Chart for the Diffusion Coefficients of Gases at High Pressures," Journal of Chemical Engineering of Japan, Vol. 7, No. 6, 1974, pp. 417-420. doi: $10.1252 /$ jcej.7.417

[63] Colin, O., and Rudgyard, M., "Development of High-Order TaylorGalerkin Schemes for Unsteady Calculations," Journal of Computational Physics, Vol. 162, No. 2, 2000, pp. 338-371. doi: $10.1006 /$ jeph. 2000.6538

[64] Choi, Y., and Merkle, C. L., "The Application of Preconditioning in Viscous Flows," Journal of Computational Physics, Vol. 105, No. 2 , 1993, pp. 207-223. doi:10.1006/jcph.1993.1069

[65] Venkateswaran, S., and Merkle, C. L., "Dual Time-Stepping and Preconditioning for Unsteady Computations," AIAA Paper 1995-0078, Jan. 1995, pp. 1-14.
[66] Lacaze, G., and Oefelein, J. C., "Modeling High-Density-Gradient Flows at Supercritical Pressures," 49th AIAA/ASME/SAE/ASEE Joint Propulsion Conference, AIAA Paper 2013-3717, 2013.

[67] Roe, P., "Approximate Riemann Solvers, Parameter Vectors and Difference Schemes," Journal of Computational Physics, Vol. 43, No. 2, 1981, pp. 357-372. doi:10.1016/0021-9991(81)90128-5

[68] Van Leer, B., "Towards the Ultimate Conservative Difference Scheme IV. A New Approach to Numerical Convection," Journal of Computational Physics, Vol. 23, No. 3, 1977, pp. 276-299. doi:10.1016/0021-9991(77)90095-X

[69] Jorgenson, P., and Turkel, E., "Central Difference TVD Schemes for Time Dependent and Steady State Problems," Journal of Computational Physics, Vol. 107, No. 2, 1993, pp. 297-308. doi:10.1006/jcph.1993.1145

[70] Poinsot, T., and Lele, S., "Boundary Conditions for Direct Simulation of Compressible Viscous Flows," Journal of Computational Physics, Vol. 101, No. 1, 1992, pp. 104-129. doi:10.1016/0021-9991(92)90046-2

[71] Baum, M., Poinsot, T. J., and Thévenin, D., "Accurate Boundary Conditions for Multicomponent Reactive Flows," Journal of Computational Physics, Vol. 116, No. 2, 1994, pp. 247-261. doi:10.1006/jcph.1995.1024

[72] Okong'o, N., and Bellan, J., "Consistent Boundary Conditions for Multicomponent Real Gas Mixtures Based on Characteristic Waves," Journal of Computational Physics, Vol. 176, No. 2, 2002, pp. 330-344. doi: $10.1006 /$ jcph.2002.6990

[73] Granet, V., Vermorel, O., Leonard, T., Gicquel, L., and Poinsot, T., "Comparison of Nonreflecting Outlet Boundary Conditions for Compressible Solvers on Unstructured Grids," AIAA Journal, Vol. 48, No. 10 , 2010, pp. $2348-2364$ doi:10.2514/1.J050391

[74] Papamoschou, D., and Roshko, A., "The Compressible Turbulent Shear Layer: An Experimental Study," Journal of Fluid Mechanics, Vol. 197, No. 1,1988 , pp. 453-477. doi:10.1017/S0022112088003325

[75] Raynal, L., "Instabilite et Entrainement a l'Interface d'Une Couche de Melange Liquide-Gaz," Ph.D. Thesis, Univ. Joseph Fourier, Grenoble, France, 1997.

[76] Juniper, M., "Structure and Stabilization of Cryogenic Spray Flames," Ph.D. Thesis, École Centrale Paris, Paris, 2001

[77] Okongó, N., Harstad, K., and Bellan, J., "Direct Numerical Simulations of O2/H2 Temporal Mixing Layers under Supercritical Conditions," AIAA Journal, Vol. 40, No. 5, 2002, pp. 914-926. doi: $10.2514 / 3.15141$

[78] Ruiz, A., "Unsteady Numerical Simulations of Transcritical Turbulent Combustion in Liquid Rocket Engines," Ph.D. Thesis, Inst. National Polytechnique de Toulouse, Toulouse, France, 2012.

[79] Jeong, J., and Hussain, F., "On the Identification of a Vortex," Journal of Fluid Mechanics, Vol. 285, No. 1, 1995, pp. 69-94. doi:10.1017/S0022112095000462

[80] Kraichnan, R. H., "Inertial Ranges in Two-Dimensional Turbulence," Physics of Fluids, Vol. 10, No. 7, 1967, pp. 1417-1423. doi:10.1063/1.1762301

[81] Batchelor, G. K., "Computation of the Energy Spectrum in Homogeneous Two-Dimensional Turbulence," Physics of Fluids, Vol. 12, No. 12 , 1969, pp. II-233-II-239. doi:10.1063/1.1692443

[82] Rutgers, M., "Forced 2-D Turbulence: Experimental Evidence of Simultaneous Inverse Energy and Forward Enstrophy Cascades," Physical Review Letters, Vol. 81, No. 11, 1998, pp. 2244-2247. doi:10.1103/PhysRevLett.81.2244

[83] Bernal, L., and Roshko, A., "Streamwise Vortex Structure in Plane Mixing Layers," Journal of Fluid Mechanics, Vol. 170, No. 1, 1986, pp. 499-525. doi:10.1017/S002211208600099X

[84] Chassaing, P., Antonia, R. A., Joly, L., Anselmet, F., and Sarkar, S., Variable Density Fluid Turbulence, Springer, New York, 2002, pp. 215 218.

[85] Reinaud, J., Joly, L., and Chassaing, P., "The Baroclinic Secondary Instability of the Two-Dimensional Shear Layer," Physics of Fluids, Vol. 12, No. 10, 2000, pp. 2489-2505. doi:10.1063/1.1289503

[86] Fontane, J., and Joly, L., "The Stability of the Variable-Density KelvinHelmholtz Billow," Journal of Fluid Mechanics, Vol. 612, Oct. 2008, pp. 237-260. doi:10.1017/S0022112008002966 
[87] Fontane, J., Joly, L., and Reinaud, J. N., "Fractal Kelvin-Helmholtz Breakups," Physics of Fluids, Vol. 20, No. 9, 2008, Paper 091109. doi:10.1063/1.2976423

[88] Hannoun, I., and List, E., "Turbulent Mixing at a Shear-Free Density Interface," Journal of Fluid Mechanics, Vol. 189, No. 1, 1988, pp. 211 234.

doi: $10.1017 / \mathrm{S} 0022112088000977$

[89] Schmitt, T., Ruiz, A., Selle, L., and Cuenot, B., "Numerical Investigation of Destabilization of Supercritical Round Turbulent Jets Using Large Eddy Simulation," Progress in Propulsion Physics, Vol. 2, EDP Sciences, Les Ulis, France, 2011, pp. 225-238.

[90] Pope, S. B., Turbulent Flows, Cambridge Univ. Press, New York, 2000, pp. 134-158.

[91] Kim, J., Moin, P., and Moser, R., "Turbulence Statistics in Fully Developed Channel Flow at Low Reynolds Number," Journal of Fluid Mechanics, Vol. 177, No. 1, 1987, pp. 133-166. doi: $10.1017 / \mathrm{S} 0022112087000892$
[92] Szepessy, S., "On the Spanwise Correlation of Vortex Shedding from a Circular Cylinder at High Subcritical Reynolds Number," Physics of Fluids, Vol. 6, No. 7, 1994, pp. 2406-2416. doi: $10.1063 / 1.868438$

[93] Moureau, V., Domingo, P., and Vervisch, L., "From Large-Eddy Simulation to Direct Numerical Simulation of a Lean Premixed Swirl Flame: Filtered Laminar Flame-PDF Modeling," Combustion and Flame, Vol. 158, No. 7, 2011, pp. 1340-1357. doi:10.1016/i.combustflame.2010.12.004

[94] Hawkes, E. R., Chatakonda, O., Kolla, H., Kerstein, A. R., and Chen, J. H., "A Petascale Direct Numerical Simulation Study of the Modelling of Flame Wrinkling for Large-Eddy Simulations in Intense Turbulence," Combustion and Flame, Vol. 159, No. 8, 2012, pp. 2690-2703. doi:10.1016/j.combustflame.2011.11.020 